Why Are Big Banks Getting

Bigger?

Ric a rdo T. Femholz and Christoffer Koch

Federal Reserve Bank of Da llas

Research Department

Working Paper 1604 


\title{
Why Are Big Banks Getting Bigger?*
}

\author{
Ricardo T. Fernholz ${ }^{\dagger}$ \\ Claremont McKenna College \\ Christoffer Koch \\ Federal Reserve Bank of Dallas
}

\author{
This Version: February 18, 2016
}

\begin{abstract}
The U.S. banking sector has become substantially more concentrated since the 1990s, raising questions about both the causes and implications of this consolidation. We address these questions using nonparametric empirical methods that characterize dynamic power law distributions in terms of two shaping factors - the reversion rates (a measure of crosssectional mean reversion) and idiosyncratic volatilities of assets for different size-ranked banks. Using quarterly data for subsidiary commercial banks and thrifts and their parent bank-holding companies, we show that the greater concentration of U.S. bank-holding company assets is a result of lower mean reversion, a result consistent with policy changes such as interstate branching deregulation and the repeal of Glass-Steagall. In contrast, the greater concentration of both U.S. commercial bank and thrift assets is a result of higher idiosyncratic volatility, yet, idiosyncratic volatility of parent bank-holding company assets fell. This contrast suggests that diversification through non-banking activities has reduced the idiosyncratic asset volatilities of the largest bank-holding companies and affected systemic risk.
\end{abstract}

Keywords: Bank Size Distributions, Bank Structure, Dynamic Power Laws, Financial Stability, Non-Bank Activities, Nonparametric Methods, Systemic Risk

JEL Codes: G21, C81, E58, C14

*The views expressed in this paper are those of the authors alone and do not necessarily reflect the views of the Federal Reserve Bank of Dallas or the Federal Reserve System. We would like to thank Derek Lemoine, Karen Lewis, and Stephen Terry for their helpful comments. Any errors or omissions are the sole responsibility of the authors.

†500 E. Ninth St., Claremont, CA 91711.rfernholz@cmc.edu

+1909607 1692 .

‡2200 North Pearl Street, Dallas, TX 75201. christoffer.koch@dal.frb.org. +12149225173. 


\section{Contents}

1 Introduction $\quad 4$

2 Data $r$

3 A Nonparametric Approach to the Bank Size Distribution $\quad 9$

3.1 Setup and Results . . . . . . . . . . . . . . . . . . . 10

3.2 Gibrat's Law, Zipf's Law, and Pareto Distributions . . . . . . . . . . . . . . . 16

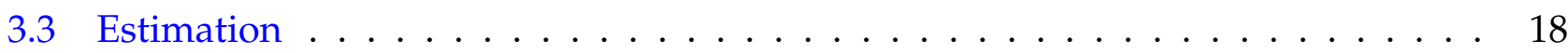

4 Empirical Results $\quad 21$

4.1 Point Estimates . . . . . . . . . . . . . . . . . . . . 22

4.2 Confidence Intervals and Statistical Significance . . . . . . . . . . . . . . 27

5 Conclusion $r$

$\begin{array}{lr}\text { References } & 31\end{array}$

$\begin{array}{lr}\text { Tables and Figures } & 34\end{array}$ 


\section{List of Tables}

1 Idiosyncratic volatilities $\sigma_{k}$ and minus the reversion rates $\alpha_{k}$ averaged by quartiles for U.S. BHCs, commercial banks, and thrifts. . . . . . . . . . . . . . . . . 34

\section{List of Figures}

1 Share of total assets held by the largest U.S. BHCs for $1986-2014$. . . . . . . 35

2 Share of total assets held by the largest U.S. commercial banks for 1960 - 2014. . 35

3 Share of total assets held by the largest U.S. thrifts for $1984-2011$. . . . . . . . 36

$4 \sigma_{k}$ for different ranked U.S. BHCs . . . . . . . . . . . . . . . . . . . 36

$5 \quad \sigma_{k}$ for different ranked U.S. commercial banks . . . . . . . . . . . . . . . . 37

$6 \quad \sigma_{k}$ for different ranked U.S. thrifts $\ldots \ldots \ldots \ldots \ldots \ldots \ldots$

$7 \quad$ Minus the reversion rates $\left(\alpha_{k}\right)$ for different ranked U.S. BHCs . . . . . . . . . 38

8 Minus the reversion rates $\left(\alpha_{k}\right)$ for different ranked U.S. commercial banks . . . 38

9 Minus the reversion rates $\left(\alpha_{k}\right)$ for different ranked U.S. thrifts . . . . . . . . . . . 39

10 Assets share held versus predicted by largest U.S. BHCs for 1986 Q2 - 1997 Q4 . 39

11 Assets share held versus predicted by largest U.S. BHCs for 1998 Q1 - 2014 Q4 . 40

12 Assets share held versus predicted by largest U.S. banks for 1960 Q4 - 1998 Q1 . 40

13 Assets share held versus predicted by largest U.S. banks for 1998 Q2 - 2014 Q4 . 41

14 Assets share held versus predicted by largest U.S. thrifts for 1984 Q1 - 1998 Q1 41

15 Assets share held versus predicted by largest U.S. thrifts for 1998 Q2 - 2011 Q4 42

$16 \sigma_{k}$ and $95 \%$ confidence intervals for different ranked U.S. BHCs . . . . . . . . . 42

$17 \sigma_{k}$ and $95 \%$ confidence intervals for different ranked U.S. BHCs . . . . . . . . 43

$18 \sigma_{k}$ and $95 \%$ confidence intervals for different ranked U.S. commercial banks . . 43

$19 \sigma_{k}$ and $95 \%$ confidence intervals for different ranked U.S. commercial banks . . 44

$20 \sigma_{k}$ and $95 \%$ confidence intervals for different ranked U.S. thrifts . . . . . . . . . 44

$21 \sigma_{k}$ and $95 \%$ confidence intervals for different ranked U.S. thrifts . . . . . . . . . . 45

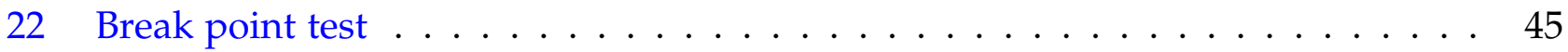




\section{Introduction}

The U.S. banking sector has undergone a tremendous transformation over the last half century. A small group of the largest banks holds more assets than ever before, a trend that accelerated after large-scale bank deregulation in the late 1990s (Kroszner and Strahan, 1999; Kroszner and Strahan, 2014). ${ }^{1}$ Indeed, the ten largest bank-holding companies (BHCs) controlled about 70 percent of total banking assets by 2010 (Figure 1). The Great Recession and Financial Crisis, characterized by the spectacular failures of large financial institutions such as Lehman Brothers and Bear Stearns, raise a number of concerns about this rise in bank asset concentration.

First, greater asset concentration may reflect fundamental changes in the nature of banking activities, such as a shift away from traditional banking towards non-banking activities within the largest financial institutions (DeYoung and Torna, 2013). This shift may contribute to added risk within financial intermediaries and hence within the banking system as a whole. Second, greater asset concentration could alter the network structure of the financial system, leading to more financial instability through greater exposure to shocks affecting large and systemically important financial institutions (SIFIs). A growing literature has emphasized the potential for idiosyncratic, firm-level shocks to have significant macroeconomic consequences (Gabaix, 2011), especially in industries such as banking where interlinkages and contagion between entities are common (Acemoglu, Carvalho, Ozdaglar, and Tahbaz-Salehi, 2012; Caballero and Simsek, 2013).

We explore the causes and implications of rising U.S. bank asset concentration using nonparametric empirical methods to describe the dynamics of the distribution of banking assets for U.S. commercial banks, thrifts, and BHCs. Our general methods, which are new to economics but are well-established in statistics, characterize the stationary distribution of bank assets in terms of only two econometric factors-the reversion rates (a measure of the rate of cross-sectional mean reversion) and idiosyncratic volatilities of bank assets. ${ }^{2}$ In particular, our new techniques yield an asymptotic statistical identity in which the distribution of bank assets

\footnotetext{
${ }^{1}$ Greenwood and Scharfstein (2013) and Philippon (2015) provide detailed analyses of the growth and evolution of the U.S. financial sector more broadly.

${ }^{2}$ Fernholz (2016b) presents the methodology in detail. For an application to the U.S. wealth distribution, see Fernholz (2016a).
} 
is described by the relationship

$$
\text { bank asset concentration }=\frac{\text { idiosyncratic volatility of bank assets }}{\text { reversion rates of bank assets }} \text {. }
$$

This identity, which obtains under minimal assumptions, shows that bank asset concentration is decreasing in reversion rates and increasing in idiosyncratic volatility. We are thus able to simultaneously investigate changes in both idiosyncratic bank asset volatility and the power law structure of the bank size distribution in a unified and robust econometric framework.

How do we interpret these two shaping econometric factors? The reversion rates of bank assets measure the different growth rates of different sized banks and encompass economic mechanisms such as regulatory and competition policy in the banking sector (Kroszner and Strahan, 1999; Kroszner and Strahan, 2014) as well as preferences, constraints, and strategic choices that drive asset growth for different sized banks (Corbae and D'Erasmo, 2013). The idiosyncratic asset volatilities measure the intensity of firm-specific shocks. These include unanticipated changes to bank liabilities and defaults on bank assets caused by shocks to borrowers' production technologies (Corbae and D'Erasmo, 2013). One of our novel contributions is to measure the changing magnitude of these shocks for both BHCs and their subsidiary commercial banks and thrifts. This exercise reveals the changing nature of diversification through non-banking activities for the largest U.S. financial institutions. It also reveals changes in one important potential source of contagion and systemic risk—idiosyncratic volatility (Acemoglu et al., 2012).

Using quarterly data on the assets of commercial banks, thrifts, and their parent BHCs, we estimate reversion rates and idiosyncratic volatilities of bank assets over a period during which the size distribution of these three categories of financial intermediaries became more concentrated. Our estimates reveal that the cause of higher concentration among both U.S. commercial banks and thrifts after the mid-1990s is an increase in idiosyncratic asset volatility, especially for the largest banks and thrifts. In contrast, we find that the primary driver of higher concentration among BHCs during this same time period is a fall in cross-sectional mean reversion as measured by the reversion rates of bank assets-the idiosyncratic volatilities of BHCs' total asset holdings actually decreased after the mid-1990s.

The fall in the idiosyncratic asset volatilities for BHCs is surprising given the observed rise 
in idiosyncratic asset volatilities for commercial banks and thrifts, many of which are subsidiaries of BHCs. This contrast suggests that diversification through non-banking activities has more than offset the higher volatilities of BHCs' traditional banking assets. The fall in idiosyncratic BHC asset volatility also reveals the surprising result that even as one source of potential contagion — concentration-has intensified, another important source-idiosyncratic volatility—has diminished. In other words, bigger banks are not necessarily riskier banks.

From 1975 to 2015, commercial bank assets as a share of GDP increased by about 70 percent. Not only did the U.S. banking system grow in size relative to the economy as a whole, but its composition and concentration also drastically changed starting in the 1990s (Janicki and Prescott, 2006). Over the last three decades, for example, the number of U.S. commercial banks has fallen from more than 14,000 to less than 6,000 while the average size of commercial banks has simultaneously increased five-fold in terms of real total assets. Several explanations for these changes have been proposed, including the gradual removal of interstate branching restrictions combined with increasing returns to scale (Hughes, Mester, and Moon, 2001; Wheelock and Wilson, 2012) and the repeal of the Glass-Steagall Act through the passage of the Gramm-Leach-Bliley Act in 1999 (Lucas, 2013). Our findings regarding the decrease in the reversion rates of BHC assets are consistent with these structural and policy changes, since these changes are the very economic factors that affect asset growth rates for the largest financial institutions.

One of this paper's central contributions is to connect and extend three different and disparate literatures-power laws, bank size distributions, and the importance of idiosyncratic shocks for aggregate economic outcomes. This is accomplished using nonparametric empirical methods for dynamic power law distributions that characterize the role of idiosyncratic shocks as a shaping force of the bank size distribution.

Our rank-based empirical methods are new to economics, but are well-established and the subject of active research in statistics. ${ }^{3}$ These empirical techniques are flexible and allow us to estimate and quantify the distributional effect of idiosyncratic volatilities across every rank in the bank size distribution. Furthermore, our methods are robust and avoid model misspecification issues since they allow for asset growth rates and volatilities that vary across

\footnotetext{
${ }^{3}$ See, for example, Banner, Fernholz, and Karatzas (2005), Pal and Pitman (2008), Ichiba, Papathanakos, Banner, Karatzas, and Fernholz (2011), and Shkolnikov (2011).
} 
different bank characteristics including rank. In this sense, our approach extends earlier analyses based on Gibrat's law (1931). We also provide techniques for estimating reversion rates and idiosyncratic volatilities using panel data and for generating confidence intervals around these estimates.

Idiosyncratic volatility is a root cause of contagion and systemic risk emanating from networks and also a contributing factor for aggregate volatility. A recent literature emphasizes the potential for entity-specific volatility to affect aggregate volatility both in closed (Carvalho and Grassi, 2015) and open economy environments (Di Giovanni and Levchenko, 2012). Gabaix (2011), for example, estimates that approximately one-third of U.S. output volatility can be explained by idiosyncratic shocks to the 100 largest domestic firms. Similarly, Carvalho and Gabaix (2013) show that "fundamental volatility" - volatility only derived from microeconomic shocks-may be an important contributor to aggregate volatility and its evolution over time. They also point to the growth of the financial sector as the chief cause of the recent rise of macroeconomic volatility that put an end to the Great Moderation (Stock and Watson, 2003).

By any measure of importance, the banking sector includes some of the largest and most interconnected U.S. corporates. In fact, over the last 15 years about a quarter of corporate profits accrued to the financial sector, peaking at a 40 percent share in 2002. ${ }^{4}$ Acemoglu et al. (2012) analyze how interconnections across industries allow for the possibility of cascade effects in which microeconomic, idiosyncratic shocks lead to aggregate fluctuations. The central role of the financial sector as a hub of the payment and credit system makes the analysis of idiosyncratic volatilities in the banking sector all the more important. Furthermore, the combination of complexity and opacity among financial intermediaries gives idiosyncratic volatilities in that sector an added significance (Caballero and Simsek, 2013). Indeed, the failure of financial institutions like Lehman Brothers or Bear Stearns often lead to greater dislocation than failures in other industries. We contribute to this literature by providing empirical estimates of idiosyncratic asset volatilities for different ranked U.S. financial intermediaries and describing the changes in these volatilities since the 1990s.

Many researchers have identified the special relevance of the size distribution of the banking sector. Kashyap and Stein (2000) and Ghossoub and Reed (2015), for example, analyze how

\footnotetext{
${ }^{4}$ National Income and Product Accounts (NIPA) table 6.16
} 
the bank size distribution influences the propagation of monetary policy. Gray and Malone (2008) discuss the implications of different bank size distributions for large scale private-public risk transfers. Beck, Demirgüç-Kunt, and Levine (2006) examine the relationship between the bank size distribution and banking crises.

The rest of this paper is organized as follows. Section 2 discusses the panel data we use for BHCs, commercial banks, and thrifts. Section 3 presents our nonparametric empirical methods for dynamic power law distributions and uses those methods to characterize the U.S. bank size distribution in terms of two econometric factors. This section also describes how to estimate these two shaping factors using panel data. Section 4 summarizes our main empirical results and discusses their statistical significance. Section 5 concludes.

\section{Data}

We analyze three different sets of U.S. depositories separately: (i) bank-holding companies, (ii) commercial banks, and (iii) thrifts. These institutions have to file quarterly balance sheets ("report on conditions") and income statements ("report on income") with their regulator. BHCs are regulated by the Federal Reserve, and commercial banks and thrifts are regulated by the Federal Reserve, the Office of the Comptroller of the Currency (OCC), and the Federal Deposit Insurance Company (FDIC). Note that thrifts were supervised by the Office of Thrift Supervision (OTS) until 2011.

These quarterly balance sheets are publicly available from the Federal Financial Institutions Examination Council (FFIEC) and from the Federal Reserve Bank of Chicago. Since this paper focuses on the factors that shape the size distribution, the only variable we use is total institution assets, which is variable mnemonic bhck2170 for BHCs, rcon2170 for commercial banks, and svgl2170 for thrifts. In order to enable an in kind comparison of mean reversion and idiosyncratic volatilities, we aggregate bank and thrift assets within a single bank-holding company via the regulatory high-holder variable rssd9248 (REG_HH_1_ID). For example, one of the largest U.S. multi-bank-holding companies Citicorp (RSSD ID: 3375370) holds two commercial banks Citibank, N.A. (RSSD ID: 476810) and Department Stores National Bank (RSSD ID: 3382547) as well as hundreds of non-bank entities.

We extract regulatory data from the so-called "call" reports. This is a repeated $N \times T$ 
cross-section where $N$ is the number of depository entities in the cross-section and $T$ is the quarter. Within our sample, the maximum number of BHCs per quarter is 2,338 (2005 Q2), the maximum number of commercial banks per quarter is 15,273 (1977 Q2), and the maximum number of thrifts per quarter is 4,025 (1979 Q4). The sampling of quarterly reports varies over time, with size thresholds in reporting changing the number of reporting entities. The minimum number of reporting entities is 966 BHCs (2007 Q4), 6,570 commercial banks (2014 Q4), and 638 thrifts (2011 Q4). Since our empirical approach requires a fixed number of ranks over time, we size-rank all depositories within reporting quarter and restrict our analysis to the largest $500 \mathrm{BHCs}$, the largest 3,000 commercial banks, and the largest 400 thrift institutions each quarter.

Data for commercial banks go back further in time than data for thrifts and BHCs. The available data start in 1986 Q4 for BHCs, 1960 Q4 for commercial banks, and 1984 Q1 for thrifts. Data is available until the most recent quarter for BHCs and commercial banks, and until 2011 Q4 for thrifts. Because we follow these categories of financial intermediaries over multiple decades, entry and exit as well as other factors constantly change the individual institutions that occupy the top ranks. In other words, we do not follow a fixed panel of BHCs, commercial banks, or thrifts every quarter, but instead a changing set of the largest depositories in each quarter.

If we consider all BHCs together, we find that the annualized average growth rate of total assets was 7.3\% during the 1986 Q4 - 2014 Q4 time period. Similarly, for all commercial banks together and all thrifts together, we find that the annualized average growth rates of total assets were 7.5\% and 1.0\% during the 1960 Q4 - 2014 Q4 and 1984 Q1 - 2011 Q4 time periods, respectively.

\section{A Nonparametric Approach to the Bank Size Distribution}

We use the nonparametric empirical methods for dynamic power law distributions detailed by Fernholz (2016b) to characterize the U.S. distribution of bank assets. ${ }^{5}$ These methods are well-established in statistics, and yield an asymptotic identity that describes the distribution

\footnotetext{
${ }^{5}$ For brevity, we refer directly to Fernholz (2016b) on several occasions and thus leave out certain technical details and proofs.
} 
of bank assets according to the relationship

$$
\text { bank asset concentration }=\frac{\text { idiosyncratic volatility of bank assets }}{\text { reversion rates of bank assets }} \text {. }
$$

This econometric identity motivates our empirical strategy. In particular, equation 3.1 implies that any increase in bank asset concentration must be caused, in an econometric sense, by either an increase in idiosyncratic asset volatility or a decrease in reversion rates.

\subsection{Setup and Results}

\section{Bank Asset Dynamics}

Consider a banking economy that consists of $N>1$ banks. Time is continuous and denoted by $t \in[0, \infty)$, and uncertainty in this economy is represented by a filtered probability space $\left(\Omega, \mathcal{F}, \mathcal{F}_{t}, P\right)$. Let $\mathbf{B}(t)=\left(B_{1}(t), \ldots, B_{M}(t)\right), t \in[0, \infty)$, be an $M$-dimensional Brownian motion defined on the probability space, with $M \geq N$. We assume that all stochastic processes are adapted to $\left\{\mathcal{F}_{t} ; t \in[0, \infty)\right\}$, the augmented filtration generated by $\mathbf{B}$.

The total assets of each bank $i=1, \ldots, N$ in this economy are given by the process $a_{i}$. Each of these asset processes evolves according to the stochastic differential equation

$$
d \log a_{i}(t)=\mu_{i}(t) d t+\sum_{z=1}^{M} \delta_{i z}(t) d B_{z}(t)
$$

where $\mu_{i}$ and $\delta_{i z}, z=1, \ldots, M$, are measurable and adapted processes. The growth rates and volatilities $\mu_{i}$ and $\delta_{i z}$ are general and essentially unrestricted, having only to satisfy a few basic regularity conditions. ${ }^{6}$ Indeed, equation (3.2) together with these regularity conditions implies that the asset processes for the banks in the economy are continuous semimartingales, which represent a broad class of stochastic processes. ${ }^{7}$ According to the martingale representation theorem (Nielsen, 1999), any plausible continuous process for asset holdings can be written in the nonparametric form of equation (3.2). This lack of structure allows for asset growth rates and volatilities that vary across different bank characteristics and hence provides a framework

\footnotetext{
${ }^{6}$ These conditions ensure basic integrability of equation (3.2) and require that no two banks' assets are perfectly correlated over time. See Appendix A of Fernholz (2016b) for details.

${ }^{7}$ Continuous semimartingales are more general than Itô processes, which are common in the continuous-time finance literature (Nielsen, 1999). For a detailed discussion, see Karatzas and Shreve (1991).
} 
that is more general than analyses based on the equal growth rates and volatilities of Gibrat's law (Gabaix, 1999; Gabaix, 2009).

It is useful to describe the dynamics of total assets for all banks in the economy, which we denote by $a(t)=a_{1}(t)+\cdots+a_{N}(t)$. In order to do so, we first characterize the covariance of assets across different banks over time. For all $i, j=1, \ldots, N$, let the covariance process $\rho_{i j}$ be given by

$$
\rho_{i j}(t)=\sum_{z=1}^{M} \delta_{i z}(t) \delta_{j z}(t)
$$

Applying Itô's Lemma to equation (3.2), it is not hard to show that the dynamics of the process for total assets in the economy $a$ are given by

$$
d \log a(t)=\mu(t) d t+\sum_{i=1}^{N} \sum_{z=1}^{M} \theta_{i}(t) \delta_{i z}(t) d B_{z}(t), \quad \text { a.s., }
$$

where

$$
\mu(t)=\sum_{i=1}^{N} \theta_{i}(t) \mu_{i}(t)+\frac{1}{2}\left(\sum_{i=1}^{N} \theta_{i}(t) \rho_{i i}(t)-\sum_{i, j=1}^{N} \theta_{i}(t) \theta_{j}(t) \rho_{i j}(t)\right),
$$

and, for all $i=1, \ldots, N, \theta_{i}(t)$ is the share of total assets held by bank $i$ at time $t$,

$$
\theta_{i}(t)=\frac{a_{i}(t)}{a(t)}
$$

\section{Rank-Based Bank Asset Dynamics}

In order to characterize the distribution of bank assets, it is necessary to consider the dynamics of bank assets by rank. To accomplish this, we introduce notation for bank rank based on total asset holdings. For $k=1, \ldots, N$, let $a_{(k)}(t)$ represent the assets held by the bank with the $k$-th most assets of all the banks in the economy at time $t$, so that

$$
\max \left(a_{1}(t), \ldots, a_{N}(t)\right)=a_{(1)}(t) \geq a_{(2)}(t) \geq \cdots \geq a_{(N)}(t)=\min \left(a_{1}(t), \ldots, a_{N}(t)\right) .
$$

Next, let $\theta_{(k)}(t)$ be the share of total assets held by the $k$-th largest bank at time $t$, so that

$$
\theta_{(k)}(t)=\frac{a_{(k)}(t)}{a(t)}
$$


for $k=1, \ldots, N$.

The next step is to describe the dynamics of the ranked bank asset processes $a_{(k)}$ and ranked asset share processes $\theta_{(k)}, k=1, \ldots, N$. We introduce the notion of a local time in order to describe these dynamics. This is necessary as we cannot simply apply Itô's Lemma in this setting since the rank function is not differentiable.

For any continuous process $x$, the local time at 0 for $x$ is the process $\Lambda_{x}$ defined by

$$
\Lambda_{x}(t)=\frac{1}{2}\left(|x(t)|-|x(0)|-\int_{0}^{t} \operatorname{sgn}(x(s)) d x(s)\right) .
$$

As detailed by Karatzas and Shreve (1991), the local time for $x$ measures the amount of time the process $x$ spends near zero. As we demonstrate below, local times are closely related to the rate at which the asset holdings of different banks cross-sectionally revert to the mean.

To be able to link bank rank (denoted by $k$ ) to bank index (denoted by $i$ ), let $p_{t}$ be the random permutation of $\{1, \ldots, N\}$ such that for $1 \leq i, k \leq N$,

$$
p_{t}(k)=i \quad \text { if } \quad a_{(k)}(t)=a_{i}(t)
$$

This definition implies that $p_{t}(k)=i$ whenever bank $i$ is the $k$-th largest bank in the economy. It is not difficult to show that for all $k=1, \ldots, N$, the dynamics of the ranked bank asset processes $a_{(k)}$ and ranked asset share processes $\theta_{(k)}$ are given by ${ }^{89}$

$$
d \log a_{(k)}(t)=d \log a_{p_{t}(k)}(t)+\frac{1}{2} d \Lambda_{\log a_{(k)}-\log a_{(k+1)}}(t)-\frac{1}{2} d \Lambda_{\log a_{(k-1)}-\log a_{(k)}}(t), \quad \text { a.s., }
$$

and

$$
d \log \theta_{(k)}(t)=d \log \theta_{p_{t}(k)}(t)+\frac{1}{2} d \Lambda_{\log \theta_{(k)}-\log \theta_{(k+1)}}(t)-\frac{1}{2} d \Lambda_{\log \theta_{(k-1)}-\log \theta_{(k)}}(t), \quad \text { a.s. }
$$

To understand equation (3.11), note that the local time terms in this equation only contribute to $a_{(k)}(t)$ if the $k$-th largest bank's assets either fall to the level of the $(k+1)$-th largest bank's assets (this corresponds to $\Lambda_{\left.\log a_{(k)}-\log a_{(k+1)}\right)}$ or rise to the level of the $(k-1)$-th largest bank's

\footnotetext{
${ }^{8}$ Throughout this paper, we shall use the convention that $\Lambda_{\log a_{(0)}-\log a_{(1)}}(t)=\Lambda_{\log a_{(N)}-\log a_{(N+1)}}(t)=0$. We shall also write $d x_{p_{t}(k)}(t)$ to refer to the process $\sum_{i=1}^{N} 1_{\left\{i=p_{t}(k)\right\}} d x_{i}(t)$.

${ }^{9} \mathrm{~A}$ formal derivation of these equations is provided by Fernholz (2016b).
} 
assets (this corresponds to $\Lambda_{\log a_{(k-1)}-\log a_{(k)}}$ ). In the former case, the positive local time term ensures that the asset holdings of the $k$-th largest bank are always larger than those of the $(k+1)$-th largest bank. Conversely, in the latter case, the negative local time term ensures that the $k$-th largest bank is always smaller than the $(k-1)$-th largest bank. A similar logic applies to equation (3.12) for the ranked asset share processes $\theta_{(k)}$.

Using the definition of the asset shares $\theta_{i}(t)$ from equation (3.6), if we subtract equation (3.4) from equation (3.2), then we have that for all $i=1, \ldots, N$,

$$
d \log \theta_{i}(t)=\mu_{i}(t) d t+\sum_{z=1}^{M} \delta_{i z}(t) d B_{z}(t)-\mu(t) d t-\sum_{i=1}^{N} \sum_{z=1}^{M} \theta_{i}(t) \delta_{i z}(t) d B_{z}(t)
$$

Because equation (3.12) describes the dynamics of the ranked asset share processes $\theta_{(k)}$ in terms of the dynamics of the asset share processes $\theta_{i}$, we can substitute equation (3.13) into equation (3.12) to get that

$$
\begin{aligned}
d \log \theta_{(k)}(t)=( & \left.\mu_{p_{t}(k)}(t)-\mu(t)\right) d t+\sum_{z=1}^{M} \delta_{p_{t}(k) z}(t) d B_{z}(t)-\sum_{i=1}^{N} \sum_{z=1}^{M} \theta_{i}(t) \delta_{i z}(t) d B_{z}(t) \\
& +\frac{1}{2} d \Lambda_{\log \theta_{(k)}-\log \theta_{(k+1)}}(t)-\frac{1}{2} d \Lambda_{\log \theta_{(k-1)}-\log \theta_{(k)}}(t)
\end{aligned}
$$

a.s., for all $k=1, \ldots, N$. Equation (3.14), in turn, implies that the process $\log \theta_{(k)}-\log \theta_{(k+1)}$ satisfies, a.s., for all $k=1, \ldots, N-1$,

$$
\begin{aligned}
d\left(\log \theta_{(k)}(t)-\log \theta_{(k+1)}(t)\right)=( & \left.\mu_{p_{t}(k)}(t)-\mu_{p_{t}(k+1)}(t)\right) d t+d \Lambda_{\log \theta_{(k)}-\log \theta_{(k+1)}(t)} \\
& -\frac{1}{2} d \Lambda_{\log \theta_{(k-1)}-\log \theta_{(k)}}(t)-\frac{1}{2} d \Lambda_{\log \theta_{(k+1)}-\log \theta_{(k+2)}}(t) \\
& +\sum_{z=1}^{M}\left(\delta_{p_{t}(k) z}(t)-\delta_{p_{t}(k+1) z}(t)\right) d B_{z}(t) .
\end{aligned}
$$

\section{Reversion Rates}

Let $\alpha_{k}$ equal the time-averaged limit of the expected growth rate of assets for the $k$-th largest bank at time $t, \mu_{p_{t}(k)}$, relative to the expected growth rate of assets for all banks in the economy, $\mu$, so that

$$
\alpha_{k}=\lim _{T \rightarrow \infty} \frac{1}{T} \int_{0}^{T}\left(\mu_{p_{t}(k)}(t)-\mu(t)\right) d t
$$


for $k=1, \ldots, N$. It is worth emphasizing that the growth rates $\mu_{p_{t}(k)}$ in equation (3.16) can vary over time and across any bank characteristics. The key insight is that by averaging these different and changing growth rates over time for each rank $k$, we obtain rank-based relative growth rates $\alpha_{k}$ that allow us to characterize the distribution of bank assets, as we shall demonstrate below.

The relative growth rates $\alpha_{k}$ are a measure of the rate at which bank assets revert to the mean. We shall refer to the $-\alpha_{k}$ as reversion rates, since lower values of $\alpha_{k}$ (and hence higher values of $-\alpha_{k}$ ) imply faster cross-sectional mean reversion.

For all $k=1, \ldots, N$, let $\kappa_{k}$ equal the time-averaged limit of the local time process $\Lambda_{\log \theta_{(k)}}-\log \theta_{(k+1)}$, so that

$$
\kappa_{k}=\lim _{T \rightarrow \infty} \frac{1}{T} \Lambda_{\log \theta_{(k)}-\log \theta_{(k+1)}}(T) .
$$

Let $\kappa_{0}=0$, as well. The parameters $\alpha_{k}$ and $\kappa_{k}$ are related by $\alpha_{k}-\alpha_{k+1}=\frac{1}{2} \kappa_{k-1}-\kappa_{k}+\frac{1}{2} \kappa_{k+1}$, for all $k=1, \ldots, N-1$. This relationship between reversion rates and local times is useful for estimating the reversion rates.

\section{Idiosyncratic Volatilities}

In a similar manner, we wish to define the time-averaged limit of the volatility of the process $\log \theta_{(k)}-\log \theta_{(k+1)}$, which measures the relative asset holdings of adjacent banks in the distribution of bank assets. For all $k=1, \ldots, N-1$, let $\sigma_{k}$ be given by

$$
\sigma_{k}^{2}=\lim _{T \rightarrow \infty} \frac{1}{T} \int_{0}^{T} \sum_{z=1}^{M}\left(\delta_{p_{t}(k) z}(t)-\delta_{p_{t}(k+1) z}(t)\right)^{2} d t
$$

As with the growth rates in equation (3.16), the asset volatilities implied by the parameters $\delta_{p_{t}(k) z}$ in equation (3.18) can vary over time and across any bank characteristics. These different and changing volatilities are averaged over time for each rank $k$, and this yields rank-based volatilities $\sigma_{k}$ that, together with the reversion rates $-\alpha_{k}$, entirely determine the shape of the distribution of bank assets.

Each volatility parameter $\sigma_{k}$ measures the standard deviation of the process $\log \theta_{(k)}-$ $\log \theta_{(k+1)}$. In the presence of both idiosyncratic, bank-specific shocks and aggregate shocks, these volatility parameters will measure only the intensity of idiosyncratic shocks since ag- 
gregate shocks that affect all banks have no impact on the relative asset holdings of adjacent banks in the distribution.

Note, however, that the volatility parameters $\sigma_{k}$ measure the idiosyncratic asset volatilities of both the $k$-th and $(k+1)$-th largest banks together (because they measure the volatility of $\log \theta_{(k)}-\log \theta_{(k+1)}$ rather than $\left.\log \theta_{(k)}\right)$. As a consequence, in order to obtain values that correspond to idiosyncratic asset volatilities for one single ranked bank, it is necessary to appropriately adjust the estimated values of $\sigma_{k}$ reported in Table 1 and Figures 4 to 6 below. In particular, these estimated values must be divided by the square root of two.

\section{The Distribution of Bank Assets}

The stable version of the process $\log \theta_{(k)}-\log \theta_{(k+1)}$ is the process $\log \hat{\theta}_{(k)}-\log \hat{\theta}_{(k+1)}$ defined by

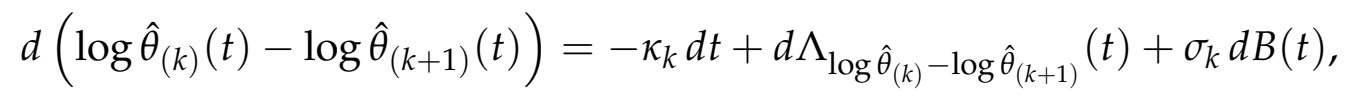

for all $k=1, \ldots, N-1 .^{10}$ The stable version of $\log \theta_{(k)}-\log \theta_{(k+1)}$ replaces all of the processes from the right-hand side of equation (3.15) with their time-averaged limits, with the

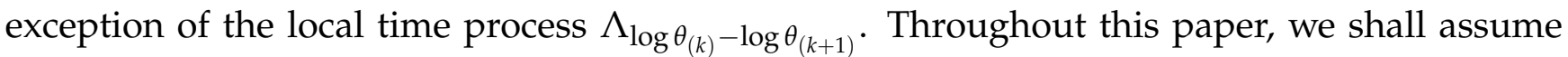
that the limits in equations (3.16)-(3.18) do in fact exist. ${ }^{11}$ By considering the stable version of these relative asset holdings processes, we are able to obtain a simple characterization of the distribution of bank assets.

Theorem 3.1. There is a stationary distribution of bank assets in this economy if and only if $\alpha_{1}+\cdots+$ $\alpha_{k}<0$, for $k=1, \ldots, N-1$. Furthermore, if there is a stationary distribution of bank assets, then for $k=1, \ldots, N-1$, this distribution satisfies

$$
E\left[\log \hat{\theta}_{(k)}(t)-\log \hat{\theta}_{(k+1)}(t)\right]=\frac{\sigma_{k}^{2}}{-4\left(\alpha_{1}+\cdots+\alpha_{k}\right)}, \quad \text { a.s. }
$$

Theorem 3.1 provides an analytic rank-by-rank characterization of the entire distribution of bank assets that matches the intuitive form of equation (3.1). ${ }^{12}$ This characterization is

\footnotetext{
${ }^{10}$ For each $k=1, \ldots, N-1$, equation (3.19) implicitly defines another Brownian motion $B(t), t \in[0, \infty)$. These Brownian motions can covary in any way across different $k$.

${ }^{11}$ Note that the existence of the limits in equations (3.16)-(3.18) is a weaker assumption than the existence of a stationary distribution of bank assets (Banner, Fernholz, and Karatzas, 2005).

${ }^{12}$ We refer the reader to Fernholz (2016b) for a proof of the theorem.
} 
achieved despite minimal assumptions on the processes that describe the dynamics of bank assets over time. Indeed, as long as the relative growth rates, volatilities, and local times that we take limits of in equations (3.16)-(3.18) do not change drastically and frequently over time, then the distribution of the stable versions of $\theta_{(k)}$ from Theorem 3.1 will accurately reflect the distribution of the true versions of these ranked asset share processes.

According to Theorem 3.1, two factors describe the bank size distribution. The first factor is the reversion rates of bank assets, measured by $-\alpha_{k}$, and the second factor is the idiosyncratic volatility of bank assets, $\sigma_{k}$. Both factors vary across different ranks in the distribution, thus going beyond simpler formulations based on the equal growth rates and volatilities imposed by Gibrat's law. The theorem shows that an increase in reversion rates lowers the concentration of bank assets, while an increase in idiosyncratic volatility raises the concentration of bank assets. ${ }^{13}$ Any change in the bank size distribution is caused by a corresponding change in at least one of these two factors that shape the distribution.

Central to our empirical approach is the implication of Theorem 3.1 that only two factors shape the distribution of bank assets. Our goal is to measure these two shaping factors and investigate how they changed over time. This analysis allows us to determine the cause, in an econometric sense, of the large increase in the concentration of U.S. bank assets observed in the last few decades.

\subsection{Gibrat's Law, Zipf's Law, and Pareto Distributions}

It is useful to see how our rank-based, nonparametric approach nests many common examples of random growth processes from other literatures as special cases. We shall focus on the influential example of Gibrat's law, and also describe the conditions that are necessary for Gibrat's law to give rise to Zipf's law.

According to Gabaix (2009), the strongest form of Gibrat's law for banks imposes asset growth rates and volatilities that do not vary across different sized banks. In terms of the reversion rates $-\alpha_{k}$ (which measure relative asset growth rates for different size-ranked banks) and idiosyncratic volatilities $\sigma_{k}$, this requirement is equivalent to there existing some common

\footnotetext{
${ }^{13}$ Note that this latter result is consistent with the results of Gabaix (2009) and Benhabib, Bisin, and Zhu (2011).
} 
$\alpha<0$ and $\sigma>0$ such that

$$
\alpha=\alpha_{1}=\cdots=\alpha_{N-1}
$$

and

$$
\sigma=\sigma_{1}=\cdots=\sigma_{N-1}
$$

In terms of equation (3.20) from Theorem 3.1, then, Gibrat's law yields asset shares that satisfy

$$
E\left[\log \hat{\theta}_{(k)}(t)-\log \hat{\theta}_{(k+1)}(t)\right]=\frac{\sigma_{k}^{2}}{-4\left(\alpha_{1}+\cdots+\alpha_{k}\right)}=\frac{\sigma^{2}}{-4 k \alpha} \quad \text { a.s., }
$$

for all $k=1, \ldots, N-1$.

The distribution of bank assets follows a Pareto distribution if a plot of asset shares as a function of rank, using log scales for both axes, appears as a straight line. ${ }^{14}$ Furthermore, if the slope of such a straight line plot is -1 , then bank asset shares obey Zipf's law (Gabaix, 1999). According to equation (3.23), for all $k=1, \ldots, N-1$, the slope of such a log-log plot in the case Gibrat's law is given by

$$
\frac{E\left[\log \hat{\theta}_{(k)}(t)-\log \hat{\theta}_{(k+1)}(t)\right]}{\log k-\log k+1} \approx-k E\left[\log \hat{\theta}_{(k)}(t)-\log \hat{\theta}_{(k+1)}(t)\right]=\frac{-k \sigma^{2}}{-4 k \alpha}=\frac{\sigma^{2}}{4 \alpha} .
$$

Equation (3.24) shows that Gibrat's law yields a Pareto distribution in which the log-log plot of asset shares versus rank has slope $\sigma^{2} / 4 \alpha<0$, which is equivalent to the Pareto distribution having parameter $-4 \alpha / \sigma^{2}>0$. Furthermore, we see that bank asset shares obey Zipf's law only if $\sigma^{2}=-4 \alpha$, in which case the log-log plot has slope -1 .

Theorem 3.1 thus demonstrates that Gibrat's law and Zipf's law are special cases of general power law distributions in which asset growth rates and volatilities potentially vary across different ranks in the distribution. Indeed, equation (3.20) implies that any power law exponent can obtain in any part of the distribution curve. This flexibility is a novel feature of our empirical methodology and is necessary to accurately match the empirical bank size distribution. As we show in Section 4, asset growth rates and volatilities for all categories of financial intermediaries that we examine differ across ranks in a statistically significant and economically meaningful way.

\footnotetext{
${ }^{14}$ See the discussions in Newman (2006) and Gabaix (2009).
} 


\subsection{Estimation}

Perhaps the most important implication of Theorem 3.1 is that an understanding of rank-based bank asset dynamics is sufficient to describe the entire distribution of U.S. bank assets. According to the theorem, it is not necessary to directly model and estimate bank asset dynamics by name, denoted by index $i$. Instead, if we can estimate the time-averaged rank-based relative growth rates, $\alpha_{k}$, and the time-averaged rank-based volatilities, $\sigma_{k}$, then we can describe the full distribution of bank assets using equation (3.20).

Using our detailed panel data for U.S. bank assets, we can estimate these rank-based parameters directly. This is accomplished using discrete-time approximations of the continuous processes that yielded Theorem 3.1.

For the estimation of the volatility parameters $\sigma_{k}$, we use the discrete-time approximation of equation (3.18) above. In particular, these estimates are given by

$$
\sigma_{k}^{2}=\frac{1}{T-1} \sum_{t=1}^{T-1}\left[\left(\log \theta_{p_{t}(k)}(t+1)-\log \theta_{p_{t}(k+1)}(t+1)\right)-\left(\log \theta_{p_{t}(k)}(t)-\log \theta_{p_{t}(k+1)}(t)\right)\right]^{2}
$$

for all $k=1, \ldots, N-1$. Note that $T$ is the total number of quarters in the time period over which we estimate these parameters. Equation (3.25) shows that the parameters $\sigma_{k}$ are estimated by measuring the standard deviations of changes over time in the log asset shares of the $k$-th largest bank relative to the $(k+1)$-th largest bank (changes over time in $\log \theta_{p_{t}(k)}(t)-$ $\left.\log \theta_{p_{t}(k+1)}(t)\right)$ for all ranks $k=1, \ldots, N-1$.

We also wish to estimate the rank-based relative growth rates $\alpha_{k}$. In order to accomplish this, we first estimate the local time parameters $\kappa_{k}$ and then use the relationship that exists between these local times and the $\alpha_{k}$ parameters.

Lemma 3.2. The relative growth rate parameters $\alpha_{k}$ and the local time parameters $\kappa_{k}$ satisfy

$$
\alpha_{k}=\frac{1}{2} \kappa_{k-1}-\frac{1}{2} \kappa_{k}
$$

for all $k=1, \ldots, N-1$, and $\alpha_{N}=-\left(\alpha_{1}+\cdots+\alpha_{N-1}\right)$. 
Lemma 3.3. The ranked asset share processes $\theta_{(k)}$ satisfy the stochastic differential equation

$$
\begin{aligned}
d \log \left(\theta_{p_{t}(1)}(t)+\cdots+\theta_{p_{t}(k)}(t)\right)= & d \log \left(\theta_{(1)}(t)+\cdots+\theta_{(k)}(t)\right) \\
& -\frac{\theta_{(k)}(t)}{2\left(\theta_{(1)}(t)+\cdots+\theta_{(k)}(t)\right)} d \Lambda_{\log \theta_{(k)}-\log \theta_{(k+1)}(t), \quad \text { a.s., }}
\end{aligned}
$$

for all $k=1, \ldots, N$.

Lemmas 3.2 and 3.3 together allow us to generate estimates of the rank-based relative growth rates $\alpha_{k} \cdot{ }^{15}$ In order to accomplish this, we first estimate the local time processes $\Lambda_{\log \theta_{(k)}-\log \theta_{(k+1)}}$ using the discrete-time approximation of equation (3.27). This discrete-time approximation implies that for all $k=1, \ldots, N$,

$$
\begin{aligned}
& \log \left(\theta_{p_{t}(1)}(t+1)+\cdots+\theta_{p_{t}(k)}(t+1)\right)-\log \left(\theta_{p_{t}(1)}(t)+\cdots+\theta_{p_{t}(k)}(t)\right)= \\
& \log \left(\theta_{p_{t+1}(1)}(t+1)+\cdots+\theta_{p_{t+1}(k)}(t+1)\right)-\log \left(\theta_{p_{t}(1)}(t)+\cdots+\theta_{p_{t}(k)}(t)\right) \\
& \quad-\frac{\theta_{p_{t}(k)}(t)}{2\left(\theta_{p_{t}(1)}(t)+\cdots+\theta_{p_{t}(k)}(t)\right)}\left(\Lambda_{\log \theta_{(k)}-\log \theta_{(k+1)}}(t+1)-\Lambda_{\log \theta_{(k)}-\log \theta_{(k+1)}}(t)\right),
\end{aligned}
$$

which, after simplification and rearrangement, yields ${ }^{16}$

$$
\begin{gathered}
\Lambda_{\log \theta_{(k)}-\log \theta_{(k+1)}}(t+1)-\Lambda_{\log \theta_{(k)}-\log \theta_{(k+1)}}(t)=\left[\log \left(\theta_{p_{t+1}(1)}(t+1)+\cdots+\theta_{p_{t+1}(k)}(t+1)\right)\right. \\
\left.-\log \left(\theta_{p_{t}(1)}(t+1)+\cdots+\theta_{p_{t}(k)}(t+1)\right)\right] \frac{2\left(\theta_{p_{t}(1)}(t)+\cdots+\theta_{p_{t}(k)}(t)\right)}{\theta_{p_{t}(k)}(t)} .
\end{gathered}
$$

As with our estimates of the volatility parameters $\sigma_{k}$, we estimate the values of the local times in equation (3.29) for $t=1, \ldots, T-1$, where $T$ is the total number of quarters in the time period over which we are estimating. We also set $\Lambda_{\log \theta_{(k)}-\log \theta_{(k+1)}}(1)=0$, for all $k=1, \ldots, N$.

Equation (3.29) states that the change in the local time process $\Lambda_{\log \theta_{(k)}}-\log \theta_{(k+1)}$ is increasing in the difference between the time $t+1$ asset holdings of the largest $k$ banks at time $t+1$ and the time $t+1$ asset holdings of the largest $k$ banks at time $t$, a nonnegative number. ${ }^{17}$ Of

\footnotetext{
${ }^{15}$ We refer the reader to Fernholz (2016b) for the simple proofs of Lemmas 3.2 and 3.3.

${ }^{16}$ Note that $\theta_{p_{t}(k)}(t+1)$ denotes the assets at time $t+1$ of the bank that is $k$-th largest at time $t$, while $\theta_{p_{t+1}(k)}(t+1)$ denotes the assets at time $t+1$ of the bank that is $k$-th largest at time $t+1$.

${ }^{17}$ Because of entry and exit, there are banks that appear in our data set at time $t$ but not at time $t+1$, and
} 
course, this difference measures the intensity of cross-sectional mean reversion, since a large difference implies that the largest $k$ banks at time $t$ have seen their assets grow substantially slower than some other subset of banks that had smaller total asset holdings at time $t$ and are now themselves the largest banks in the economy.

After estimating the local times in equation (3.29), we then use equation (3.17) to generate estimates of $\kappa_{k}$ according to

$$
\kappa_{k}=\frac{1}{T} \Lambda_{\log \theta_{(k)}-\log \theta_{(k+1)}}(T),
$$

for all $k=1, \ldots, N$. Finally, we can use the relationship between the parameters $\alpha_{k}$ and $\kappa_{k}$ established by Lemma 3.2. This is accomplished via equation (3.26), which yields estimates of each $\alpha_{k}$ using our estimates of the parameters $\kappa_{k}$ from equation (3.30). Note that according to Lemma 3.2, the reversion rates $-\alpha_{k}$, which measure the rate of cross-sectional mean reversion, are increasing in the local time parameters $\kappa_{k}$. This is not surprising given our observation from equation (3.29) that the estimated local time processes $\Lambda_{\log \theta_{(k)}-\log \theta_{(k+1)}}$ are measuring the intensity of mean reversion.

After estimating the parameters $\alpha_{k}$ and $\sigma_{k}$ for each rank $k=1, \ldots, N$, we smooth these estimates across different ranks using a standard Gaussian kernel smoother. Using these smoothed estimates, we calculate the sum of the absolute values of the difference between the observed asset shares $\theta_{(k)}$ and those predicted by our estimates according to equation (3.20) from Theorem 3.1. Next, we smooth the estimated parameters $\alpha_{k}$ and $\sigma_{k}$ a second time and again calculate the absolute deviation between the observed asset shares and those predicted by equation (3.20). This process of smoothing the estimated parameters and then calculating the absolute deviation between prediction and data is repeated until this deviation is minimized. ${ }^{18}$

One of the principle motivations of this paper is the changes in the bank size distribution that have occurred in the last few decades. Figures 1 to 3 show these substantial changes over time for bank-holding companies, commercial banks, and thrifts. According to the figures, the U.S. bank size distribution began to transition from one distribution to another at some point

vice versa. The calculations in equations (3.25) and (3.29), however, require that banks stay in the data set for two consecutive quarters. It is thus necessary to restrict our calculations at each time $t$ to only those banks that are in the data set at time $t$ and time $t+1$.

${ }^{18}$ More precisely, we calculate the absolute deviation between prediction and data by smoothing the parameters $\alpha_{k}$ and $\sigma_{k}$ between 1 and 100 times and then choosing the number of smoothings that achieves the lowest total absolute deviation within this range. 
in the 1990s. In the context of our empirical approach, this transition implies that a long-run change in reversion rates $-\alpha_{k}$ and idiosyncratic volatilities $\sigma_{k}$ occurred at this same point in time. It is necessary, then, to estimate the quarter in which this transition began as well as two sets of reversion rates and volatilities-one before the transition, and one after it.

In order to estimate these objects, we use a procedure similar to the smoothing procedure that minimizes the absolute deviation between prediction and data as described above. First, we select a quarter as the start date for the transition from one distribution to another. Next, we estimate two sets of reversion rates $-\alpha_{k}$ and idiosyncratic volatilities $\sigma_{k}$ using data before and after our transition start date (this follows the procedure described above). Finally, we calculate the sum of the absolute values of the difference between the observed asset shares $\theta_{(k)}$ and those predicted by our estimated reversion rates and volatilities according to equation (3.20). Note that the predicted asset shares are different before and after the transition start date, since the estimated factors differ for these two periods as well. We repeat this procedure over a set of plausible start dates for the transition from one distribution to another and then choose the transition start date that minimizes the sum of absolute deviations between prediction and data. ${ }^{19}$

\section{Empirical Results}

The intuitive version of our statistical identity in equation (3.1) motivates our empirical strategy in this paper. By estimating reversion rates $-\alpha_{k}$ and idiosyncratic volatilities $\sigma_{k}$ for U.S. bank-holding companies, commercial banks, and thrifts, we can examine how these two shaping factors changed over time. According to Theorem 3.1, this analysis offers an econometric explanation of the increased concentration in banking assets observed after the mid-1990s for all three categories of banking institutions (Figures 1 to 3). Furthermore, as emphasized by Acemoglu et al. (2012), measures of changing idiosyncratic volatilities yield information about changing U.S. financial stability.

\footnotetext{
${ }^{19}$ These plausible start dates range from the early 1990s through 2000. Start dates outside this range yield substantially higher deviations between prediction and data.
} 


\subsection{Point Estimates}

\section{Idiosyncratic Volatilities}

One of this paper's main contributions is to analytically characterize the role of idiosyncratic volatility as a shaping force of the bank size distribution. We first examine the idiosyncratic volatilities $\sigma_{k}$ across the size distribution of bank-holding companies, commercial banks, and thrifts, recalling that commercial banks and thrifts are often subsidiaries of BHCs.

Section 3 provides a procedure for estimating idiosyncratic volatilities across different ranks using panel data. In Figures 4, 5, and 6, we plot, respectively, the estimated standard deviations of the idiosyncratic volatilities of asset holdings for different ranked U.S. BHCs, commercial banks, and thrifts. These values of $\sigma_{k}$, averaged across quartiles, are also reported in the first two columns of Table 1.

Figure 4 plots the idiosyncratic asset volatilities for the 500 largest U.S. BHCs from 1986 Q2 - 1997 Q4 and then from 1998 Q1 - 2014 Q4. According to Figure 4, the idiosyncratic asset volatilities for BHCs decreased after 1997 Q4, with the largest decreases occurring for medium-sized BHCs. In section 4.2, we confirm that these changes are in fact most statistically significant for medium-sized BHCs. Similarly, Figure 5 plots the idiosyncratic asset volatilities for the 3,000 largest U.S. commercial banks from 1960 Q4 - 1998 Q1 and then from 1998 Q2 - 2014 Q4. In contrast to BHCs, this figure shows that, especially for the largest commercial banks, idiosyncratic volatilities increased after 1998 Q1. The other common subsidiary of BHCs, thrifts, also experienced a similar increase in idiosyncratic asset volatilities. Figure 6 plots the idiosyncratic volatilities for the 400 largest U.S. thrifts from 1984 Q1 - 1998 Q1 and then from 1998 Q2 - 2011 Q4 and shows this increase in the later period. Importantly, the measured decrease in the idiosyncratic asset volatilities of BHCs over time shown in Figure 4 is in stark contrast to the measured increase in the idiosyncratic asset volatilities of commercial banks and thrifts.

Our paper is the first to reveal this surprising contrast in the changes in idiosyncratic volatilities of BHC assets as compared to commercial bank and thrift assets. This estimated divergence is notable because we group commercial banks (thrifts) that are owned by the same parent BHC together into one single commercial bank (thrift) entity. After all, it would be natural to expect an increase in the idiosyncratic asset volatilities of subsidiary commercial 
banks and thrifts to coincide with an increase in the idiosyncratic asset volatilities of their parent BHCs. Figures 4 to 6, however, clearly refute this simple view.

A full analysis of the possible underlying economic causes of the opposing changes in asset volatilities of BHCs in contrast to commercial banks and thrifts is beyond the scope of this paper and likely a promising direction for future research. There are many potential causes of these changes-an exogenous structural change in the economic environment, a change in policy or incentives related to corporate governance, or an endogenous response to the removal of interstate branching restrictions (Kroszner and Strahan, 1999). Our empirical analysis in this paper only measures the distributional effect of these changes in volatility. However, by documenting these changes we are also able to draw conclusions about changing U.S. financial stability, even if the precise structural cause of these changes remains an open question.

\section{Reversion Rates}

The observed increase in the concentration of bank-holding company, commercial bank, and thrift assets in Figures 1 to 3 must be caused by either an increase in idiosyncratic volatilities $\sigma_{k}$, a decrease in reversion rates $-\alpha_{k}$, or both. Indeed, equation (3.20) from Theorem 3.1 states that

$$
E\left[\log \hat{\theta}_{(k)}(t)-\log \hat{\theta}_{(k+1)}(t)\right]=\frac{\sigma_{k}^{2}}{-4\left(\alpha_{1}+\cdots+\alpha_{k}\right)}, \quad \text { a.s. }
$$

Given the observed decrease in idiosyncratic asset volatilities of BHCs $\left(\sigma_{k}\right)$ observed in Figure 4, then, it must be that cross-sectional mean reversion $\left(-\alpha_{k}\right)$ decreased in 1998 Q1 - 2014 Q4 relative to 1986 Q2 - 1997 Q4. Figure 7 confirms that this is in fact the case-the fall in mean reversion of $\mathrm{BHC}$ assets more than offset the fall in the idiosyncratic volatility and led to the rise in $\mathrm{BHC}$ asset concentration.

Similar to BHCs, commercial bank and thrift assets also grew more concentrated after 1997, but this concentration occurs at the same time as the idiosyncratic volatilities of commercial bank and thrift assets, as measured by the parameters $\sigma_{k}$, rose. Consequently, our empirical approach does not have a clear prediction about the direction of change of the reversion rates of commercial bank and thrift assets, as measured by the parameters $-\alpha_{k}$. Figures 8 to 9 reveal that these reversion rates actually increased for the largest commercial banks and thrifts after 
1997, with the magnitude of this change larger for thrifts than for commercial banks. ${ }^{20}$ In both cases, however, these increases in cross-sectional mean reversion are of a smaller magnitude than the decrease in mean reversion for BHC assets shown in Figure 7. For commercial banks and thrifts, then, both mean reversion and idiosyncratic volatility rose, but the rise in idiosyncratic volatility ruled and led to the rise in commercial bank and thrift asset concentration.

A number of potential economic explanations can account for these observed changes in mean reversion rates. In particular, legislative changes in the mid-1990s such as the repeal of the Glass-Steagall Act that separated commercial and investment banking (Lucas, 2013) are consistent with relatively faster asset growth for the largest BHCs and hence less mean reversion. Further effects may stem from persistent effects of the liberalization of inter-state branching restrictions discussed in Kroszner and Strahan (1999) and Kroszner and Strahan (2013) or changes in the scale economies of the banking industry discussed in Wheelock and Wilson (2012) and Wheelock and Wilson (2015). Finally, to the extent that the underlying size distribution of business firms is determined by the distribution of managerial talent, it is possible that these changes in the bank size distribution are being driven by a change in managerial talent (Lucas, 1978). While it is beyond the scope of this paper, future empirical work that attempts to link these changes in the economic environment to the changes in crosssectional mean reversion we document in this paper should yield useful insight.

\section{What do we learn from the idiosyncratic volatilities and reversion rates?}

We can draw three more conclusions from our findings. First, the naive view that a more concentrated banking sector is always a riskier banking sector need not hold. A growing literature emphasizes the potential for idiosyncratic, firm-level shocks to affect aggregate macroeconomic outcomes. Within this literature, both Acemoglu et al. (2012) and Caballero and Simsek (2013) show that such contagion is likely most pernicious in industries with complex and opaque interlinkages. Given the complex interlinkages of the banking and finance industries, there are reasons to worry about both concentration of assets and idiosyncratic asset volatility. Indeed, as Gabaix (2011) shows, firm-level shocks are most likely to lead to aggregate volatility in concentrated industries that are dominated by a few large firms.

We find that U.S. bank-holding company assets have grown more concentrated since the

\footnotetext{
${ }^{20}$ The last two columns of Table 1 also report changing values of $\alpha_{k}$ averaged across quartiles.
} 
1990s while the idiosyncratic volatility of BHC assets has decreased over this same time period. Therefore, to the extent that idiosyncratic shocks might be a source of aggregate risk for the financial sector, our results show that this source of risk has decreased over the last few decades. This is true despite the increase in concentration of BHC assets. Of course, we do not directly measure systemic risk or complexity in the financial sector, so we cannot conclude that the overall threat of contagion in this sector has decreased. Instead, we show that one important source of potential contagion-idiosyncratic volatility-has diminished, even as another more obvious source-concentration—has intensified.

Second, the contrasting changes in asset volatilities for different categories of banking institutions yield insight into asset diversification. Compare Figure 4 to Figures 5 and 6. There is a rise in the idiosyncratic asset volatilities of subsidiary commercial banks and thrifts after the 1990s combined with a simultaneous fall in the idiosyncratic asset volatilities of their parent BHCs. This contrasting result suggests that the non-banking activities of BHCs have strengthened intra-institutional risk-sharing and increased diversification, changes that have more than offset the rise in the idiosyncratic volatility of BHCs' commercial banking activities. This has led to a fall in the idiosyncratic volatility of their total assets. As a consequence, idiosyncratic asset volatilities-an important source of potential contagion-for the largest U.S. financial institutions have actually declined since the 1990s. To our knowledge, this paper is the first to uncover this surprising finding.

Third, we can see from Figures 4 to 9 that the shaping parameters $\alpha_{k}$ and $\sigma_{k}$ vary across different ranks in our data sets. Such variation in growth rates and idiosyncratic volatilities across different ranks is inconsistent with Gibrat's law (Gibrat, 1931), the special case of our general approach discussed in Section 3.2. In this sense, our nonparametric empirical framework extends previous studies based on the equal growth rates and volatilities imposed by Gibrat's law in a way that allows us to better match the empirical bank size distribution. This added empirical flexibility and realism allows us to observe contrasting changes in idiosyncratic volatility for parent and subsidiary financial institutions. Because this revealed divergence has intriguing implications, the value added from our empirical framework is likely to yield similar economic and policy insight when applied to other economic questions. 


\section{Goodness of Fit}

It is useful to examine how well our rank-based empirical approach matches the data. Figure 10 shows the average share of total assets held by different ranked U.S. bank-holding companies from 1986 Q2 - 1997 Q4 together with the shares predicted for these BHCs using equation (3.20) from Theorem 3.1 estimated over this same time period. ${ }^{21}$ This figure also displays the minimum and maximum shares held by different ranked BHCs during these same years. Figure 11 shows these same quantities for different ranked U.S. BHCs from 1998 Q1 - 2014 Q4. In addition to displaying the minimum and maximum shares held by different ranked BHCs during these years, this figure also displays the size distribution at the end of the sample period (the dot-dashed blue line).

Figures 10 and 11 are constructed using the cross-sectional mean reversion and idiosyncratic volatility parameters from Figures 4 and 7. Together with equation (3.20) from Theorem 3.1, these parameter values yield stationary distribution values for each rank asset share $\theta_{(k)}$, $k=1, \ldots, N .^{22}$ As the two figures demonstrate, equation (3.20) estimated over these two different time periods is able to approximately match the observed U.S. BHC size distribution. Furthermore, the predicted shares also generate an increased concentration in BHC assets for the 1998 Q1 - 2014 Q4 time period. As detailed above (Figures 4 and 7), this increased concentration is a result of a decrease in mean reversion of asset holdings for the largest BHCs.

Figures 12 and 13 show the average share of total assets held by different ranked U.S. commercial banks for 1960 Q4 - 1998 Q1 and 1998 Q2 - 2014 Q4, respectively. These figures also report the asset shares predicted using estimates of $\alpha_{k}$ and $\sigma_{k}$ over these same time periods. The fit of equation (3.20) is slightly better for commercial banks than for BHCs, but crucially, our empirical approach yields increased predicted asset concentration for both BHCs and commercial banks for the 1998 Q1 - 2014 Q4 and 1998 Q2 - 2014 Q4 time periods, respectively. These predictions are, of course, consistent with the data and hence offer an econometric explanation for one of the central questions behind this paper.

Similarly, Figures 14 and 15 show the average share of total assets held by different ranked U.S. thrifts from 1984 Q1 - 1998 Q1 and 1998 Q2 - 2011 Q4, respectively, together with the

\footnotetext{
${ }^{21}$ The figure displays asset shares as a function of rank, using log scales for both axes. As discussed in Section 3.2, if asset shares follow a Pareto distribution, then such a figure will appear as a straight line (Newman, 2006; Gabaix, 2009).

${ }^{22}$ Note that we apply the same procedure to generate predicted asset shares for commercial banks and thrifts.
} 
shares predicted using our methods of estimation over these same time periods. As in the case of BHCs and commercial banks, these figures demonstrate the reasonably good fit of equation (3.20) from Theorem 3.1 to the observed size distribution for U.S. thrifts.

Finally, Figures 11, 13, and 15 show that the size distributions predicted by equation (3.20) for BHCs, commercial banks, and thrifts are similar to the size distributions observed at the end of the sample periods (represented by the dot-dashed blue lines in the figures). This suggests that the transition from one bank asset distribution to a more concentrated distribution starting in the 1990s appears to be complete. In the absence of any further changes in the U.S. banking environment, our results do not point to any further increases in the concentration of banking assets over the coming years.

\subsection{Confidence Intervals and Statistical Significance}

It is not possible to generate confidence intervals and p-values using classical techniques in this setting because the empirical distribution of the reversion rates $-\alpha_{k}$ and idiosyncratic volatilities $\sigma_{k}$ is unknown. However, using bootstrap resampling, it is possible to generate confidence intervals and determine the statistical significance of our results in Figures 4 to 9. Because our most interesting results relate to the changes in the idiosyncratic volatilities $\sigma_{k}$ observed across different time periods, for brevity we shall focus only on the statistical significance of these changes in this section. It is straightforward to perform a similar analysis for the reversion rates $-\alpha_{k}$ confirming that the most substantial changes observed in Figures 7 to 9 are statistically significant.

In Figures 16 to 21, we report point estimates and 95\% confidence intervals based on the results of 10,000 bootstrap resample estimates of the idiosyncratic volatilities $\sigma_{k}$ for different ranked U.S. bank-holding companies, commercial banks, and thrifts, across different time periods as in Figures 4 to $6 .{ }^{23}$ Figures 16 and 17 show that the average $\sigma_{k}$ for medium-sized BHCs for each time period is outside of the other time period's confidence interval, a result that strongly suggests that these estimates are different from each other in a statistically significant way. We confirm that this is in fact the case below. In a similar manner, Figures 18 to 21 suggest a statistically significant difference between our estimates for the largest commercial

\footnotetext{
${ }^{23}$ More precisely, the size of the confidence intervals are generated by the bootstrap resample estimates and then these intervals are centered around our point estimates from Figures 4 to 6.
} 
banks' and thrifts' idiosyncratic volatilities across different time periods.

Fortunately, questions of statistical significance are easily addressed using this same method of bootstrap resampling. Figure 22 shows the probability that the idiosyncratic volatilities $\sigma_{k}$ for different ranked U.S. BHCs from 1986 Q2 - 1997 Q4 are less than or equal to the $\sigma_{k}$ from 1998 Q1 - 2014 Q4. The figure also shows the probability that the $\sigma_{k}$ for different ranked U.S. commercial banks from 1960 Q4 - 1998 Q1 are greater than or equal to the $\sigma_{k}$ from 1998 Q2 2014 Q4 as well as the probability that the $\sigma_{k}$ for different ranked U.S. thrifts from 1984 Q1 1998 Q1 are greater than or equal to the $\sigma_{k}$ from 1998 Q2 - 2011 Q4.

Like the confidence intervals displayed in Figures 16 to 21, these probabilities are based on the results of 10,000 bootstrap resample estimates of the idiosyncratic volatilities $\sigma_{k}$. More specifically, these probabilities are generated by randomly choosing quarters from each time period and each data set (BHCs, commercial banks, and thrifts) with replacement, and then recalculating the idiosyncratic volatilities $\sigma_{k}$ for each time period as in equation (3.25). ${ }^{24}$ This process is repeated 10,000 times. Finally, we generate the probabilities in Figure 22 by examining the number of resampled data sets in which the estimated $\sigma_{k}$ in time period one is greater than (less than) or equal to the estimated $\sigma_{k}$ in time period two for commercial banks and thrifts (BHCs). This procedure is repeated for every rank in the size distribution of BHCs, commercial banks, and thrifts.

The computed probabilities shown in Figure 22 are essentially sets of p-values for the hypotheses that there were no decreases in the idiosyncratic asset volatilities for U.S. BHCs after 1997 Q4, and that there were no increases in the idiosyncratic asset volatilities for U.S. commercial banks and thrifts after 1998 Q1. As we see from the figure, then, one of the most important results discussed in this section-the rise in the idiosyncratic asset volatilities of the largest subsidiary commercial banks and thrifts after 1998 Q1-is statistically significant at the $1 \%$ level. The figure also shows that the fall in the idiosyncratic asset volatilities of mediumsized BHCs after 1997 Q4 is statistically significant at either the $1 \%$ or $5 \%$ levels, and that this fall is nearly significant at the $10 \%$ level for the largest BHCs.

\footnotetext{
${ }^{24}$ As before, these recalculated $\sigma_{k}$ are centered around our point estimates from Figures 4 to 6 .
} 


\section{Conclusion}

This paper explores the implications and causes of the growing concentration of U.S. banking assets in recent decades. In order to accomplish this, we use a nonparametric empirical approach to dynamic power law distributions in which the distribution of banking assets is characterized in terms of two econometric factors-the reversion rates and idiosyncratic volatilities of assets for different size-ranked banks. We describe how to estimate these two factors using panel data and then perform such an estimation using data on the asset holdings of subsidiary commercial banks and thrifts and their parent bank-holding companies from 1960 to the present. This paper is the first, to our knowledge, to estimate these factors and show that the greater concentration of U.S. commercial bank and thrift assets after the 1990s is a result of increased idiosyncratic asset volatility while the increased concentration of BHC assets over this same period is a result of decreased cross-sectional mean reversion (as measured by the reversion rates). Surprisingly, the idiosyncratic volatility of BHC assets actually decreased after the 1990s. Using bootstrap resampling, we show that most of these changes in volatility over time are statistically significant. Given that our empirical techniques are valid for essentially any dynamic power law distribution, a promising direction for future research may be to investigate whether changes similar to those we document in the banking and finance industries have occurred in other industries.

While our results answer questions about the cause, in an econometric sense, of the growing concentration of U.S. banking assets, they also raise a number of questions. The contrast between the increase in the idiosyncratic asset volatilities of commercial banks and thrifts and the decrease in the idiosyncratic asset volatilities of their parent BHCs is of particular interest. Because commercial banks and thrifts are subsidiaries of BHCs, this result suggests that diversification through non-banking activities has reduced the idiosyncratic volatility of BHC assets. The details as to how this diversification occurred and why there is a larger decrease for medium-sized BHCs than for large or small BHCs, however, remain open questions for future research. There also remains an open question as to why the idiosyncratic asset volatilities of commercial banks and thrifts-which are typically modeled as exogenous-increased after the mid-1990s. The decline in cross-sectional mean reversion of BHC assets is consistent with legislative changes in the mid-1990s, such as the repeal of the Glass-Steagall Act (Lucas, 
2013), that allowed large BHCs to grow even larger, as well as documented changes in the scale economies of the banking industry (Wheelock and Wilson, 2012). However, the relative impact of these different factors on the rate of cross-sectional mean reversion (the reversion rates) of BHC assets is an open question for future research.

Following the nonparametric approach described by Fernholz (2016b), this paper is the first to rigorously characterize the role of idiosyncratic asset volatility as a shaping force of the bank-size distribution. A growing literature emphasizes the potential for idiosyncratic, firm-level shocks to affect aggregate macroeconomic outcomes, especially in concentrated, complex, and interconnected industries such as banking and finance (Gabaix, 2011; Acemoglu et al., 2012; Caballero and Simsek, 2013). In this sense, our results for U.S. BHCs show that even as one obvious source of potential contagion-concentration-has intensified, another important source-idiosyncratic volatility-has diminished. Of course, we do not directly measure systemic risk in the financial sector and hence cannot conclude that the overall threat of contagion in this sector has either increased or decreased. Future research that attempts to measure these contrasting effects on the threat of contagion is likely to yield useful insight and information. 


\section{References}

Acemoglu, D., V. M. Carvalho, A. Ozdaglar, and A. Tahbaz-Salehi (2012). “The network origins of aggregate fluctuations". Econometrica 80.5, pp. 1977-2016 (cit. on pp. 4, 5, 7, 21, 24, 30).

Banner, A., R. Fernholz, and I. Karatzas (2005). "Atlas Models of Equity Markets". Annals of Applied Probability 15.4, pp. 2296-2330 (cit. on pp. 6, 15).

Beck, T., A. Demirgüç-Kunt, and R. Levine (2006). "Bank concentration, competition, and crises: First results". Journal of Banking \& Finance 30.5, pp. 1581 -1603. (Cit. on p. 8).

Benhabib, J., A. Bisin, and S. Zhu (2011). "The Distribution of Wealth and Fiscal Policy in Economies with Finitely Lived Agents". Econometrica 79.1, pp. 123-157 (cit. on p. 16).

Caballero, R. J. and A. Simsek (2013). "Fire Sales in a Model of Complexity". The Journal of Finance 68.6, pp. 2549-2587 (cit. on pp. 4, 7, 24, 30).

Carvalho, V. M. and X. Gabaix (2013). "The Great Diversification and its Undoing". The American Economic Review 103.5, pp. 1697-1727 (cit. on p. 7).

Carvalho, V. M. and B. Grassi (2015). Large Firm Dynamics and the Business Cycle. CEPR Discussion Paper No. DP10587 (cit. on p. 7).

Corbae, D. and P. D'Erasmo (2013). A Quantitative Model of Banking Industry Dynamics. mimeo, University of Wisconsin (cit. on p. 5).

DeYoung, R. and G. Torna (2013). “Nontraditional Banking Activities and Bank Failures During the Financial Crisis". Journal of Financial Intermediation 22.3, pp. 397-421 (cit. on p. 4).

Di Giovanni, J. and A. A. Levchenko (2012). "Country size, international trade, and aggregate fluctuations in granular economies". Journal of Political Economy 120.6, pp. 1083-1132 (cit. on p. 7).

Fernholz, R. T. (2016a). A Statistical Model of Inequality. arXiv:1601.04093v1 [q-fin.EC] (cit. on p. 4).

- (2016b). Empirical Methods for Dynamic Power Law Distributions in the Social Sciences. arXiv:1602.00159v1 [q-fin.EC] (cit. on pp. 4, 9, 10, 12, 15, 19, 30).

Gabaix, X. (1999). “Zipf's Law for Cities: An Explanation". Quarterly Journal of Economics 114.3, pp. $739-767$ (cit. on pp. 11, 17).

- (2009). "Power Laws in Economics and Finance". Annual Review of Economics 1.1, pp. 255294 (cit. on pp. 11, 16, 17, 26). 
Gabaix, X. (2011). “The Granular Origins of Aggregate Fluctuations”. Econometricas 79.3, pp. 733772 (cit. on pp. 4, 7, 24, 30).

Ghossoub, E. A. and R. R. Reed (2015). "The size distribution of the banking sector and the effects of monetary policy". European Economic Review 75, pp. 156-176 (cit. on p. 7).

Gibrat, R. (1931). Les inégalités économiques. Librairie du Recueil Sirey, Paris. (cit. on pp. 7, 25).

Gray, D. and S. Malone (2008). Macrofinancial Risk Analysis. Vol. 433. John Wiley \& Sons (cit. on p. 8).

Greenwood, R. and D. Scharfstein (2013). "The Growth of Finance". The Journal of Economic Perspectives, pp. 3-28 (cit. on p. 4).

Hughes, J. P., L. J. Mester, and C.-G. Moon (2001). “Are scale economies in banking elusive or illusive?: Evidence obtained by incorporating capital structure and risk-taking into models of bank production". Journal of Banking \& Finance 25.12, pp. 2169-2208 (cit. on p. 6).

Ichiba, T., V. Papathanakos, A. Banner, I. Karatzas, and R. Fernholz (2011). "Hybrid Atlas Models". Annals of Applied Probability 21.2, pp. 609-644 (cit. on p. 6).

Janicki, H. and E. S. Prescott (2006). "Changes in the size distribution of US banks: 1960-2005". FRB Richmond Economic Quarterly 92.4, pp. 291-316 (cit. on p. 6).

Karatzas, I. and S. E. Shreve (1991). Brownian Motion and Stochastic Calculus. New York, NY: Springer-Verlag (cit. on pp. 10, 12).

Kashyap, A. K. and J. C. Stein (2000). "What Do a Million Observations on Banks Say about the Transmission of Monetary Policy?" American Economic Review 90.3, pp. 407-428 (cit. on p. 7).

Kroszner, R. S. and P. E. Strahan (1999). "What Drives Deregulation? Economics and Politics of the Relaxation of Bank Branching Restrictions". Quarterly Journal of Economics, pp. 14371467 (cit. on pp. 4, 5, 23, 24).

Kroszner, R. S. and P. E. Strahan (2013). "Regulation and Deregulation of the US Banking Industry: Causes, Consequences and Implications for the Future". Economic Regulation and Its Reform: What Have We Learned? University of Chicago Press, pp. 485-543 (cit. on p. 24).

Kroszner, R. S. and P. E. Strahan (2014). "Regulation and Deregulation of the U.S. Banking Industry: Causes, Consequences and Implications for the Future". Economic Regulation and Its Reform: What Have We Learned? University of Chicago Press, pp. 485-543 (cit. on pp. 4, $5)$. 
Lucas Jr., R. E. (2013). “Glass-Steagall: A Requiem”. American Economic Review 103(3), pp. 43-47 (cit. on pp. 6, 24, 29).

Lucas Jr., R. E. (1978). "On the Size Distribution of Business Firms". Bell Journal of Economics 9.2, pp. 508-523 (cit. on p. 24).

Newman, M. E. J. (2006). Power Laws, Pareto Distributions, and Zipf's Law. arXiv:cond-mat/0412004v3 [cond-mat.stat-mech] (cit. on pp. 17, 26).

Nielsen, L. T. (1999). Pricing and Hedging of Derivative Securities. New York, NY: Oxford University Press (cit. on p. 10).

Pal, S. and J. Pitman (2008). “One-Dimensional Brownian Particle Systems with Rank-Dependent Drifts". Annals of Applied Probability 18.6, pp. 2179-2207 (cit. on p. 6).

Philippon, T. (2015). "Has the US Finance Industry Become Less Efficient? On the Theory and Measurement of Financial Intermediation". The American Economic Review 105.4, pp. 140838 (cit. on p. 4).

Shkolnikov, M. (2011). "Competing Particle Systems Evolving by Interacting Lévy Processes". Annals of Applied Probability 21.5, pp. 1911-1932 (cit. on p. 6).

Stock, J. H. and M. W. Watson (2003). "Has the business cycle changed and why?" NBER Macroeconomics Annual 2002, Volume 17. MIT Press, pp. 159-230 (cit. on p. 7).

Wheelock, D. C. and P. W. Wilson (2012). "Do large banks have lower costs? New estimates of returns to scale for US banks". Journal of Money, Credit and Banking 44.1, pp. 171-199 (cit. on pp. 6, 24, 30).

Wheelock, D. C. and P. W. Wilson (2015). The Evolution of Scale Economies in U.S. Banking. Federal Reserve Bank of St. Louis Working Paper 2015-21 (cit. on p. 24). 


\section{Tables and Figures}

Bank-Holding Companies

\begin{tabular}{|c|c|c|c|c|}
\hline \multirow[b]{2}{*}{ Rank } & \multicolumn{2}{|c|}{$\sigma_{k}$} & \multicolumn{2}{|c|}{$\alpha_{k}$} \\
\hline & 1986 Q1 - 1997 Q4 & 1998 Q1 - 2014 Q4 & 1986 Q1 - 1997 Q4 & 1998 Q1 - 2014 Q4 \\
\hline Top 25\% & $24.1 \%$ & $22.8 \%$ & $-2.33 \%$ & $-1.08 \%$ \\
\hline $25 \%-50 \%$ & $22.0 \%$ & $20.1 \%$ & $-1.44 \%$ & $-0.97 \%$ \\
\hline $50 \%-75 \%$ & $32.0 \%$ & $20.2 \%$ & $1.39 \%$ & $-0.17 \%$ \\
\hline $75 \%-100 \%$ & $19.2 \%$ & $16.7 \%$ & $-0.74 \%$ & $-0.37 \%$ \\
\hline
\end{tabular}

\section{Commercial Banks}

\begin{tabular}{|c|c|c|c|c|}
\hline \multirow[b]{2}{*}{ Rank } & \multicolumn{2}{|c|}{$\sigma_{k}$} & \multicolumn{2}{|c|}{$\alpha_{k}$} \\
\hline & 1960 Q4 - 1998 Q1 & 1998 Q2 - 2014 Q4 & 1960 Q4 - 1998 Q1 & 1998 Q2 - 2014 Q4 \\
\hline Top 25\% & $21.1 \%$ & $23.5 \%$ & $-1.40 \%$ & $-1.70 \%$ \\
\hline $25 \%-50 \%$ & $18.3 \%$ & $18.7 \%$ & $-0.83 \%$ & $-0.35 \%$ \\
\hline $50 \%-75 \%$ & $16.1 \%$ & $16.4 \%$ & $-0.58 \%$ & $-0.36 \%$ \\
\hline $75 \%-100 \%$ & $15.7 \%$ & $16.3 \%$ & $-0.34 \%$ & $-0.40 \%$ \\
\hline
\end{tabular}

\section{Thrifts}

\begin{tabular}{|c|c|c|c|}
\hline \multicolumn{2}{|c|}{$\sigma_{k}$} & \multicolumn{2}{|c|}{$\alpha_{k}$} \\
\hline 1984 Q1 - 1998 Q1 & $1998 \mathrm{Q} 2-2011 \mathrm{Q} 4$ & 1984 Q1-1998 Q1 & $1998 \mathrm{Q} 2-2011 \mathrm{Q} 4$ \\
\hline $25.0 \%$ & $29.9 \%$ & $-1.93 \%$ & $-3.37 \%$ \\
\hline $24.2 \%$ & $29.7 \%$ & $-0.83 \%$ & $-0.37 \%$ \\
\hline $20.9 \%$ & $19.4 \%$ & $-0.51 \%$ & $-0.78 \%$ \\
\hline $19.9 \%$ & $21.6 \%$ & $-0.16 \%$ & $1.34 \%$ \\
\hline
\end{tabular}

Table 1: Idiosyncratic volatilities $\sigma_{k}$ and minus the reversion rates $\alpha_{k}$ averaged by quartiles for U.S. BHCs, commercial banks, and thrifts. 


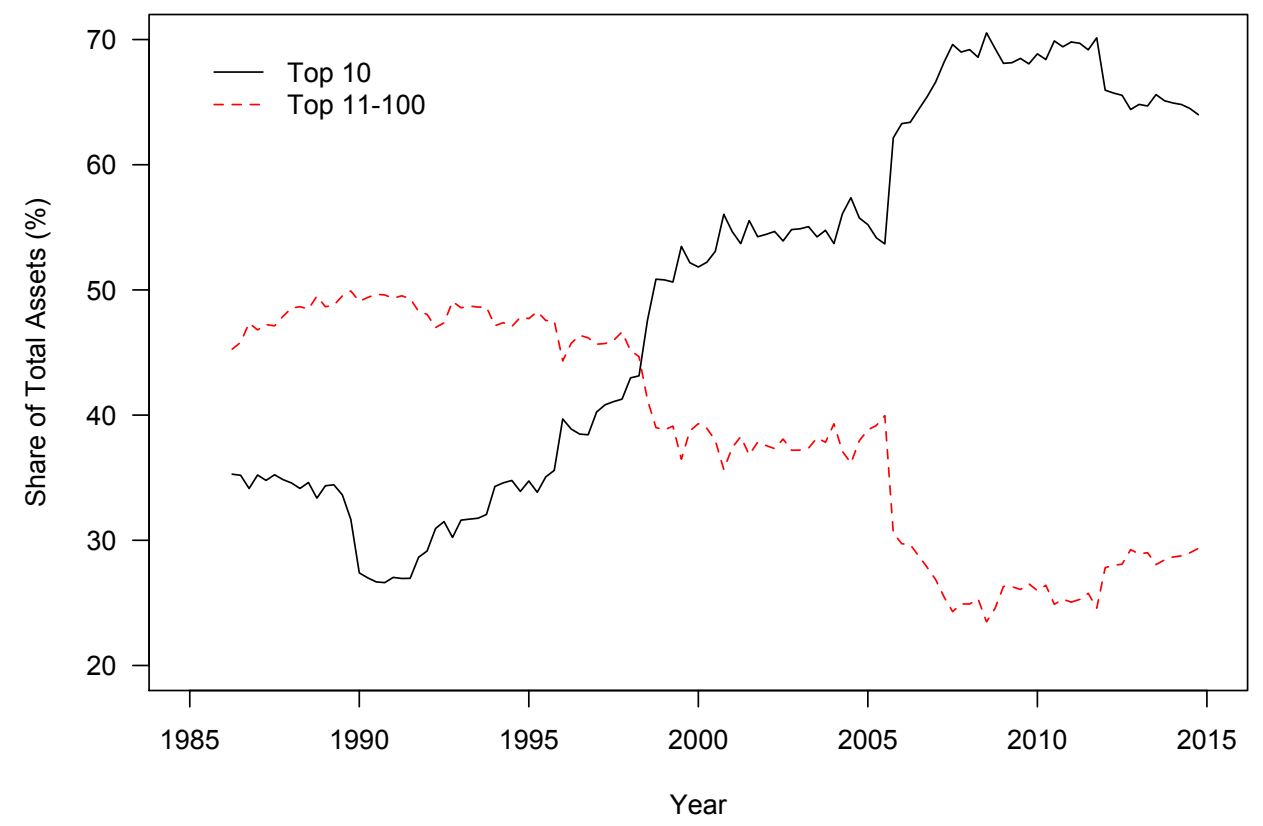

Fig. 1: Share of total assets held by the largest U.S. bank-holding companies for $1986-2014$.

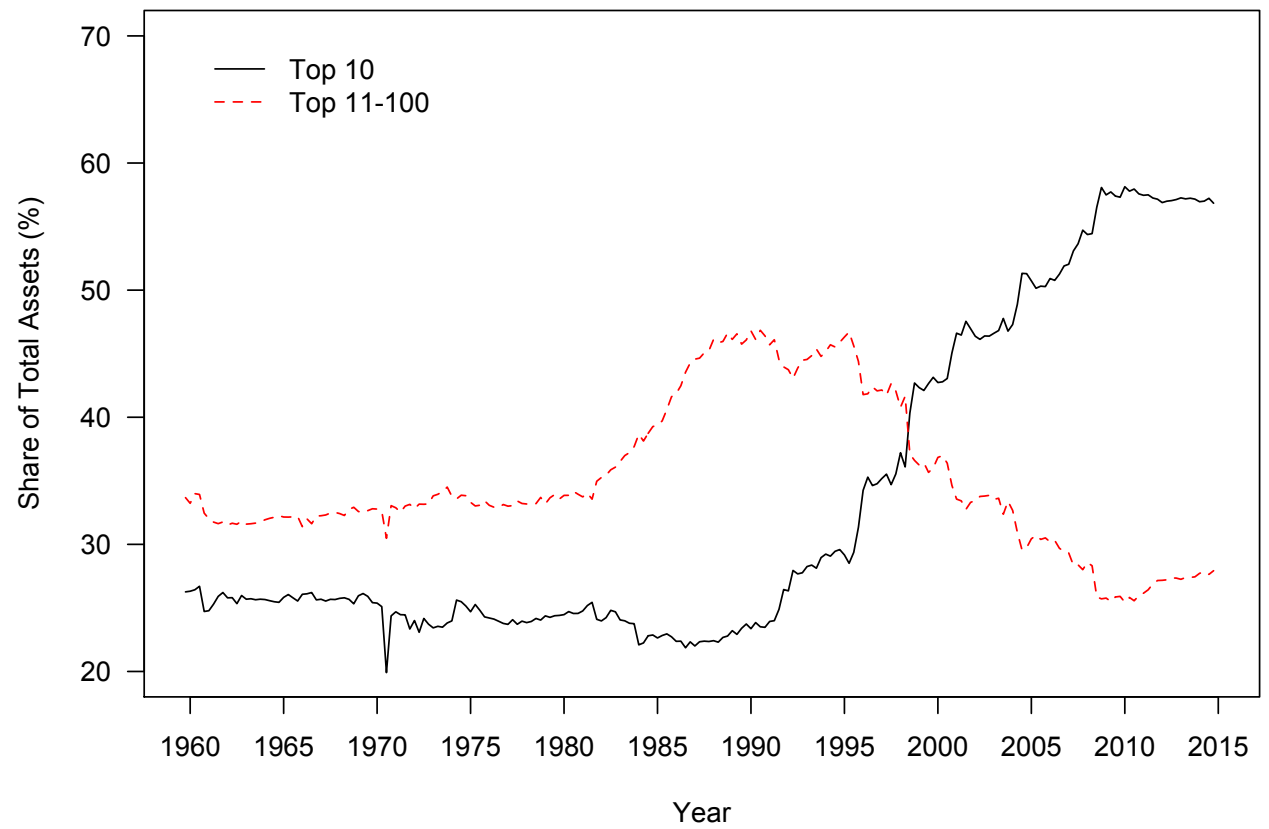

Fig. 2: Share of total assets held by the largest U.S. commercial banks for $1960-2014$. 


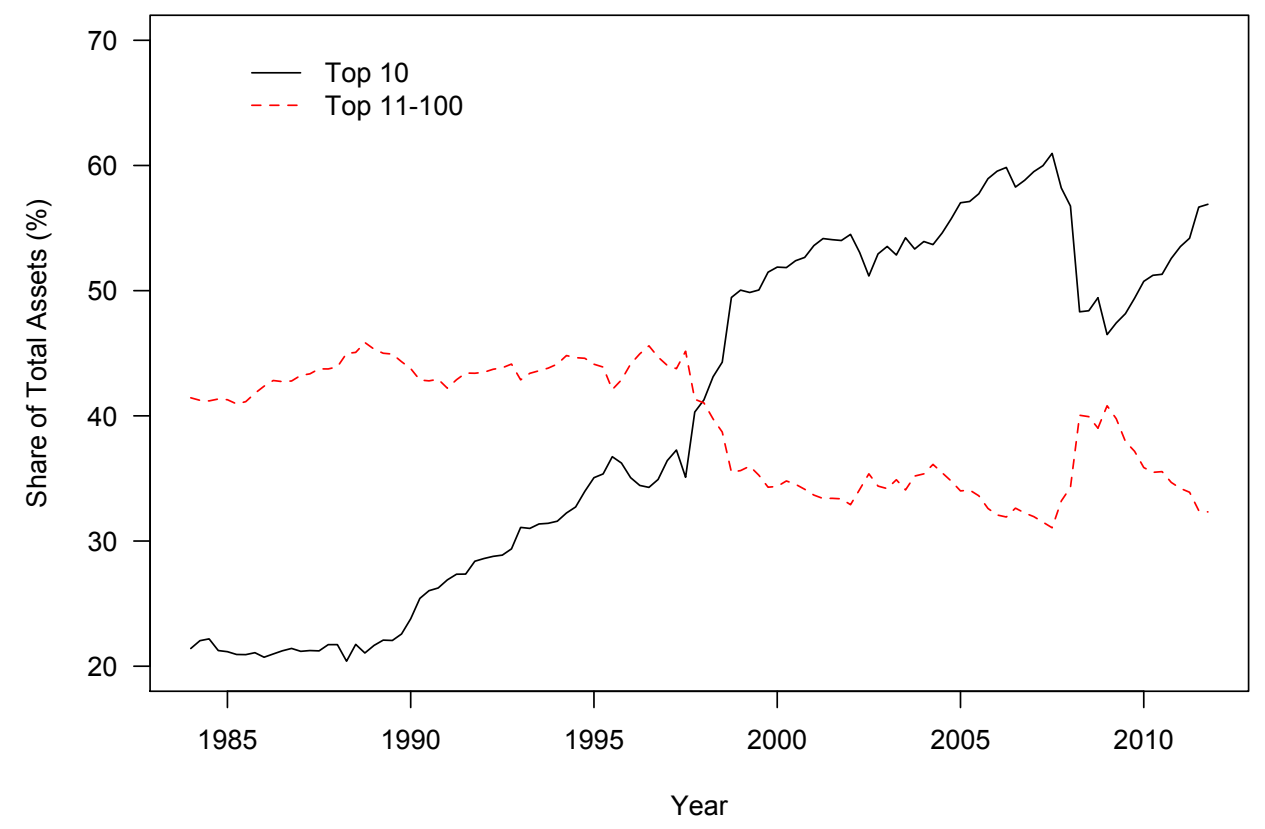

Fig. 3: Share of total assets held by the largest U.S. thrifts for $1984-2011$.

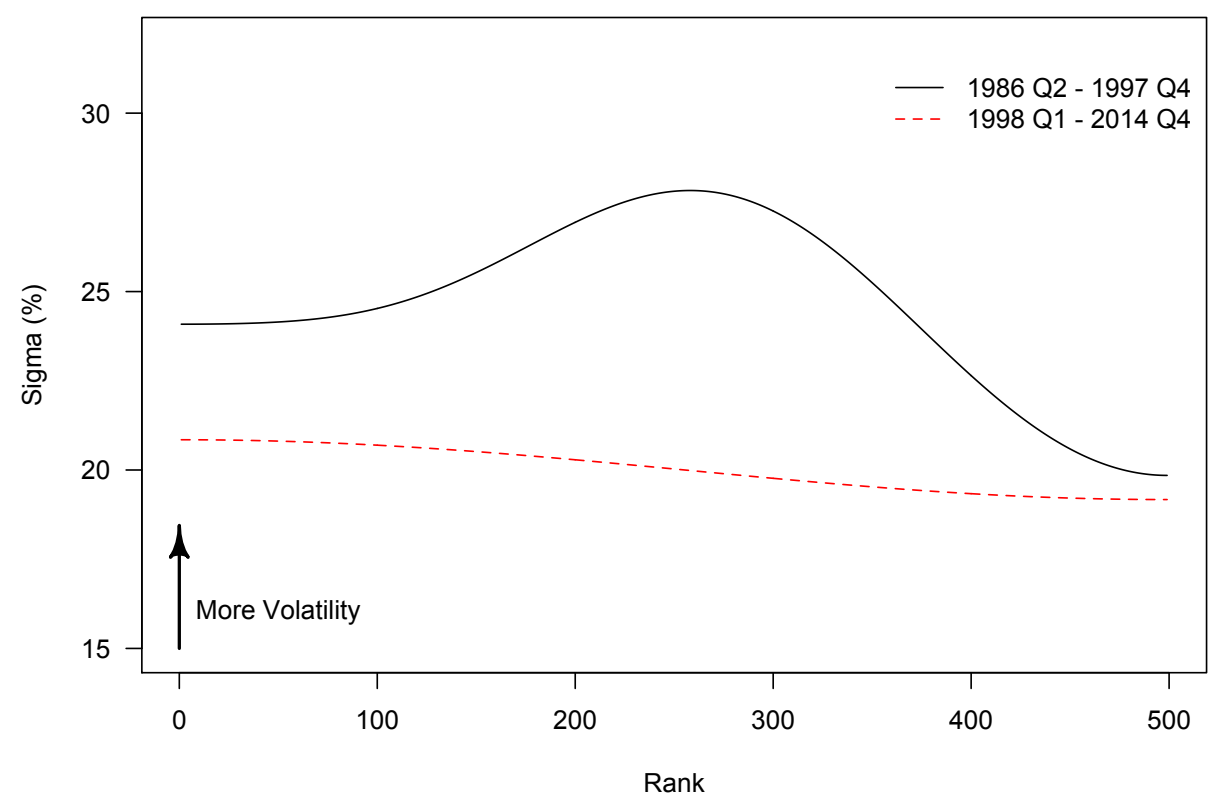

Fig. 4: Standard deviations of idiosyncratic asset volatilities $\left(\sigma_{k}\right)$ for different ranked U.S. bankholding companies. 


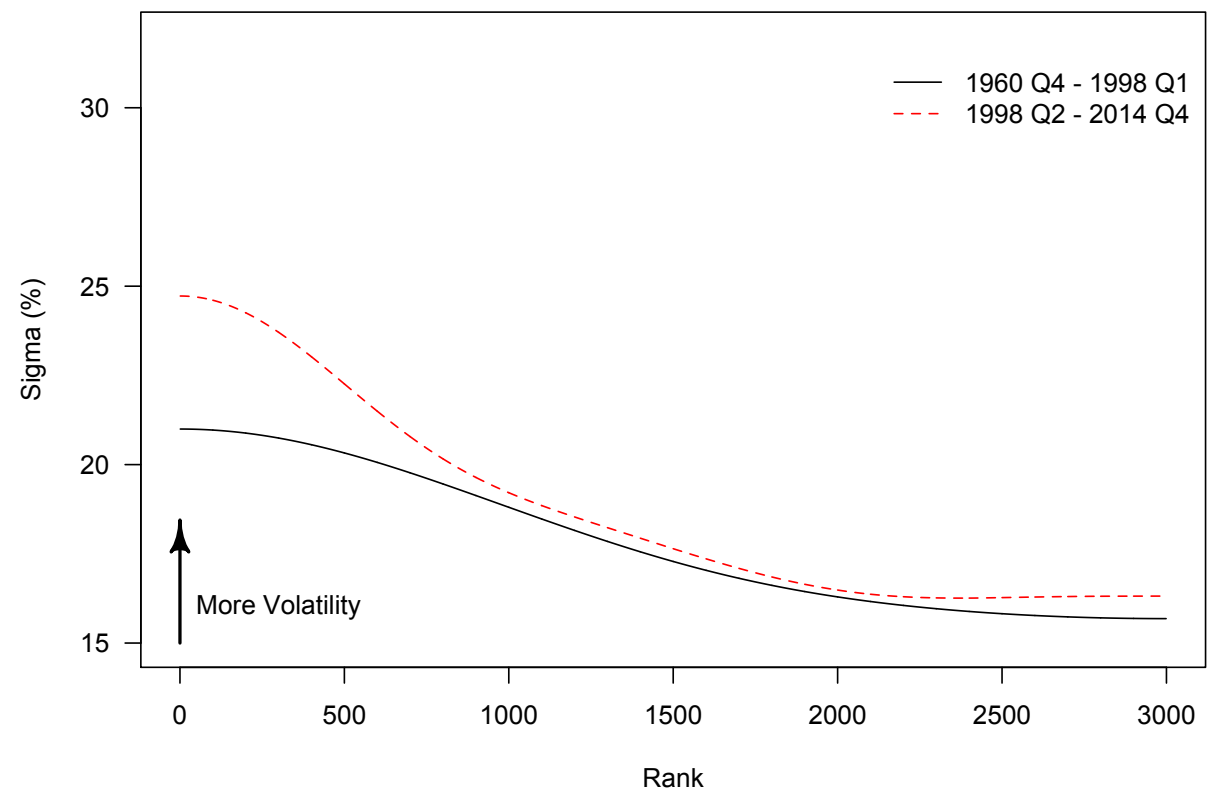

Fig. 5: Standard deviations of idiosyncratic asset volatilities $\left(\sigma_{k}\right)$ for different ranked U.S. commercial banks.

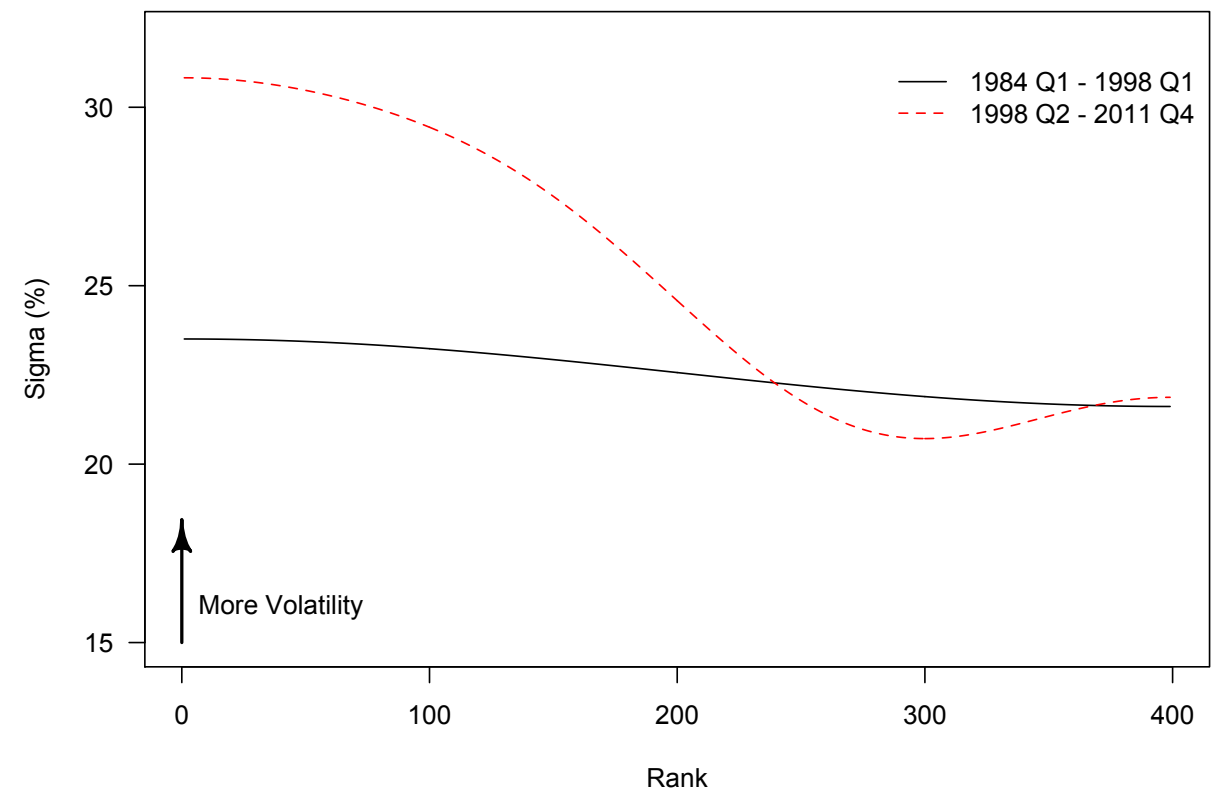

Fig. 6: Standard deviations of idiosyncratic asset volatilities $\left(\sigma_{k}\right)$ for different ranked U.S. thrifts. 


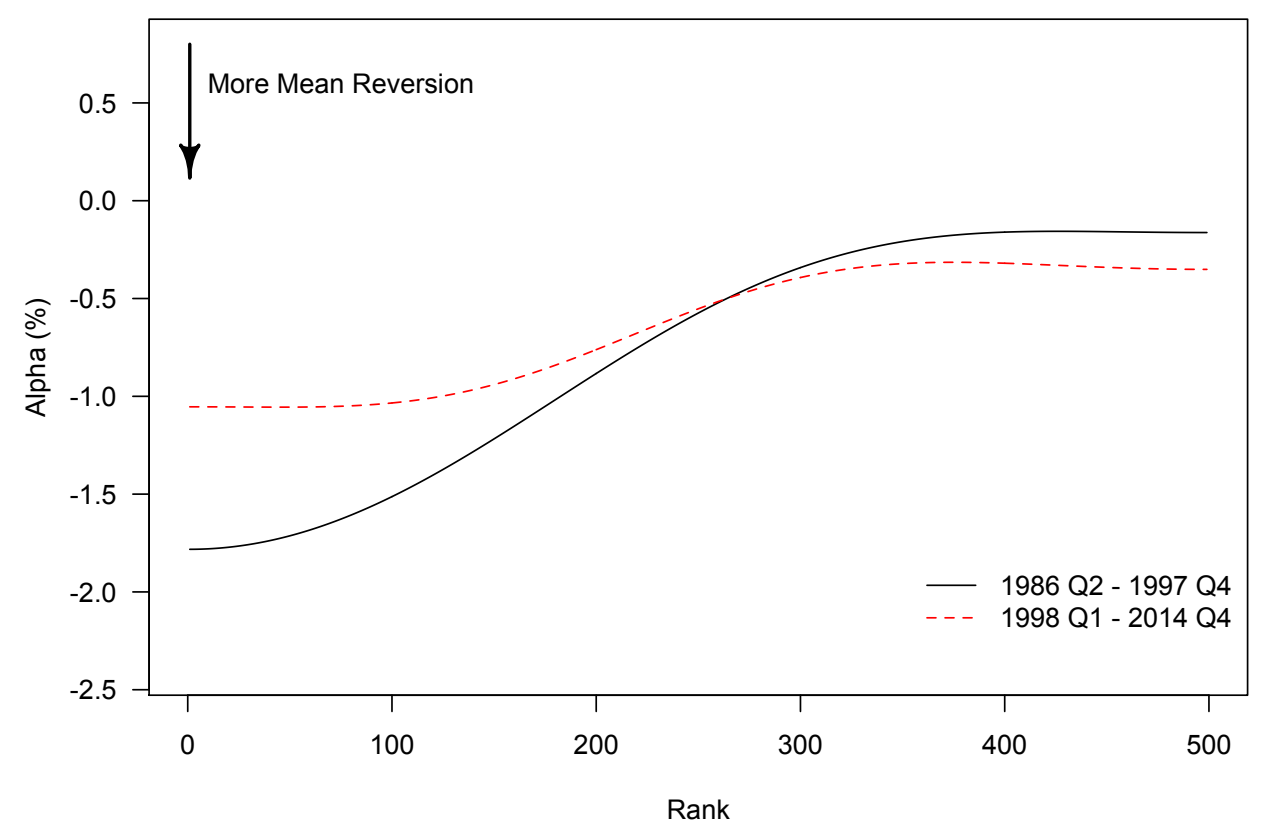

Fig. 7: Minus the reversion rates $\left(\alpha_{k}\right)$ for different ranked U.S. bank-holding companies.

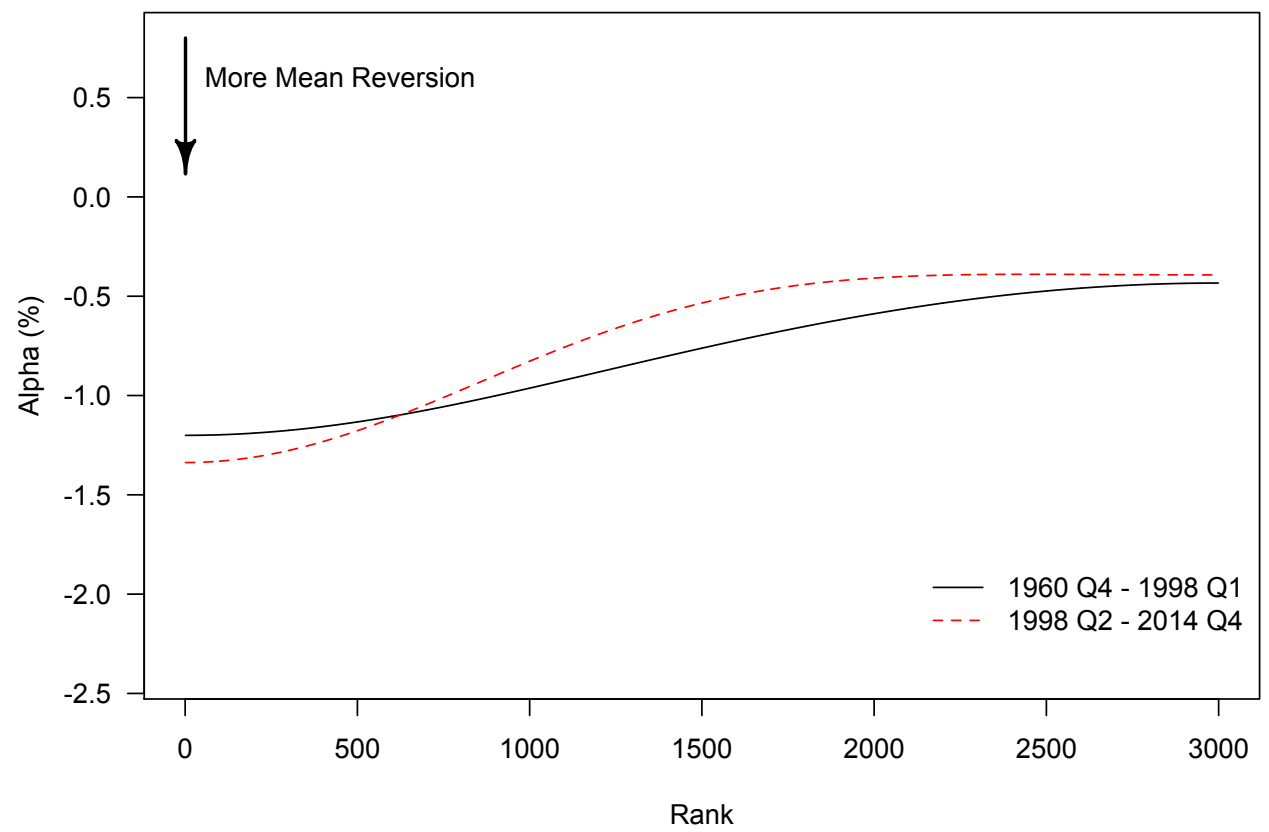

Fig. 8: Minus the reversion rates $\left(\alpha_{k}\right)$ for different ranked U.S. commercial banks. 


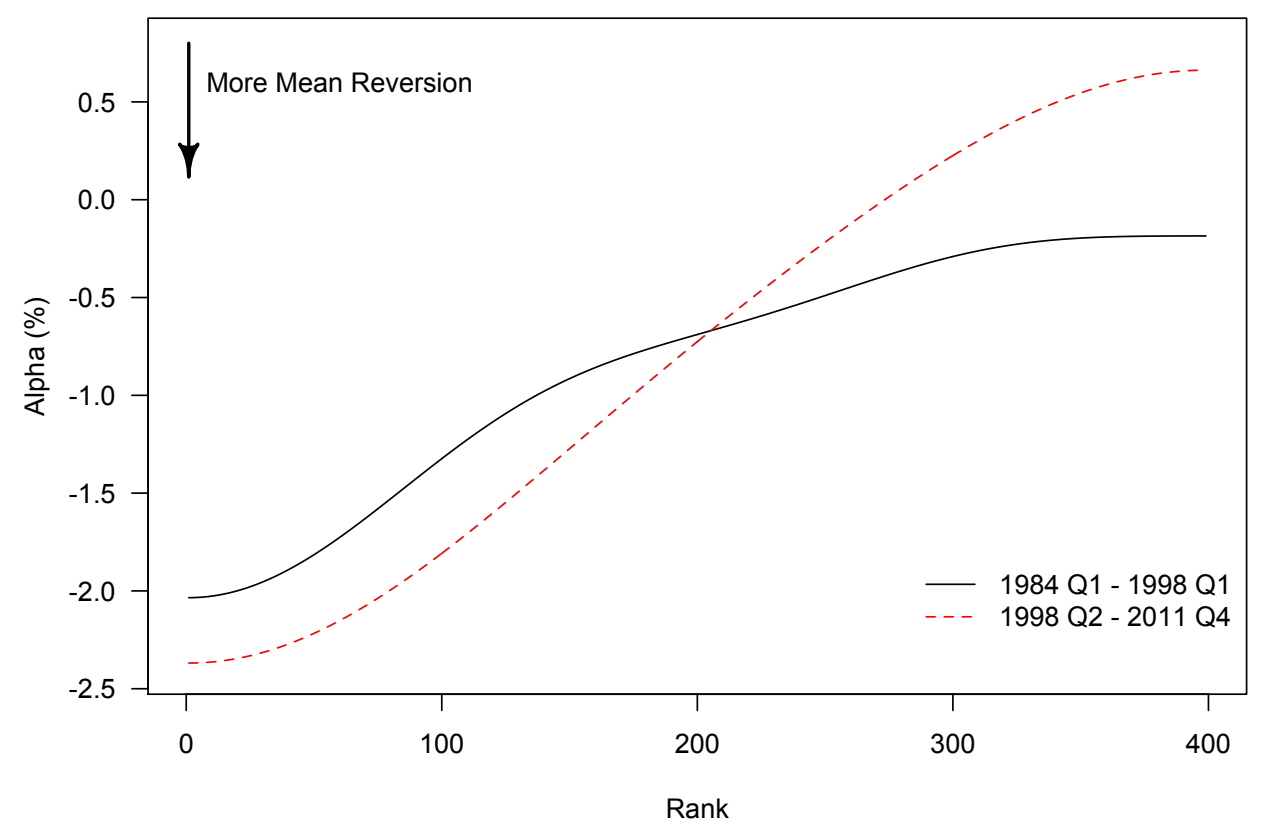

Fig. 9: Minus the reversion rates $\left(\alpha_{k}\right)$ for different ranked U.S. thrifts.

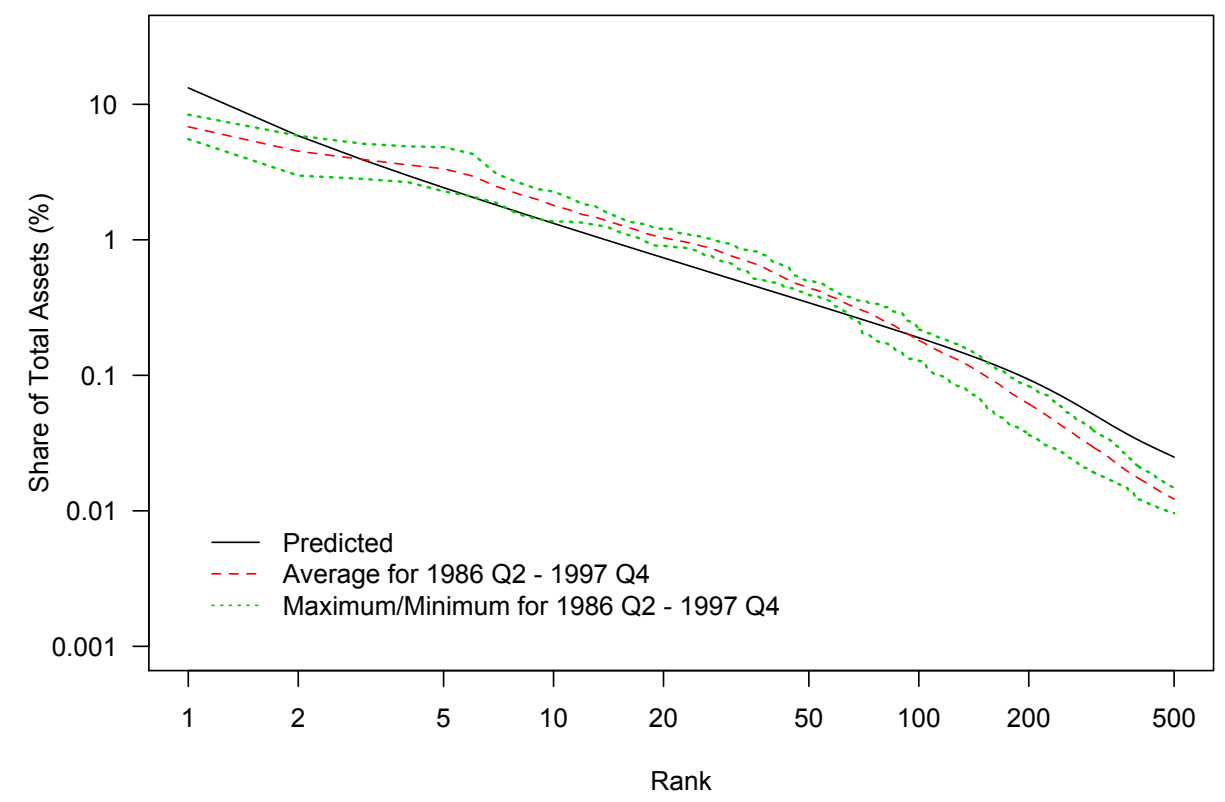

Fig. 10: Shares of total assets held by the 500 largest U.S. bank-holding companies for 1986 Q2 - 1997 Q4 as compared to the predicted shares. 


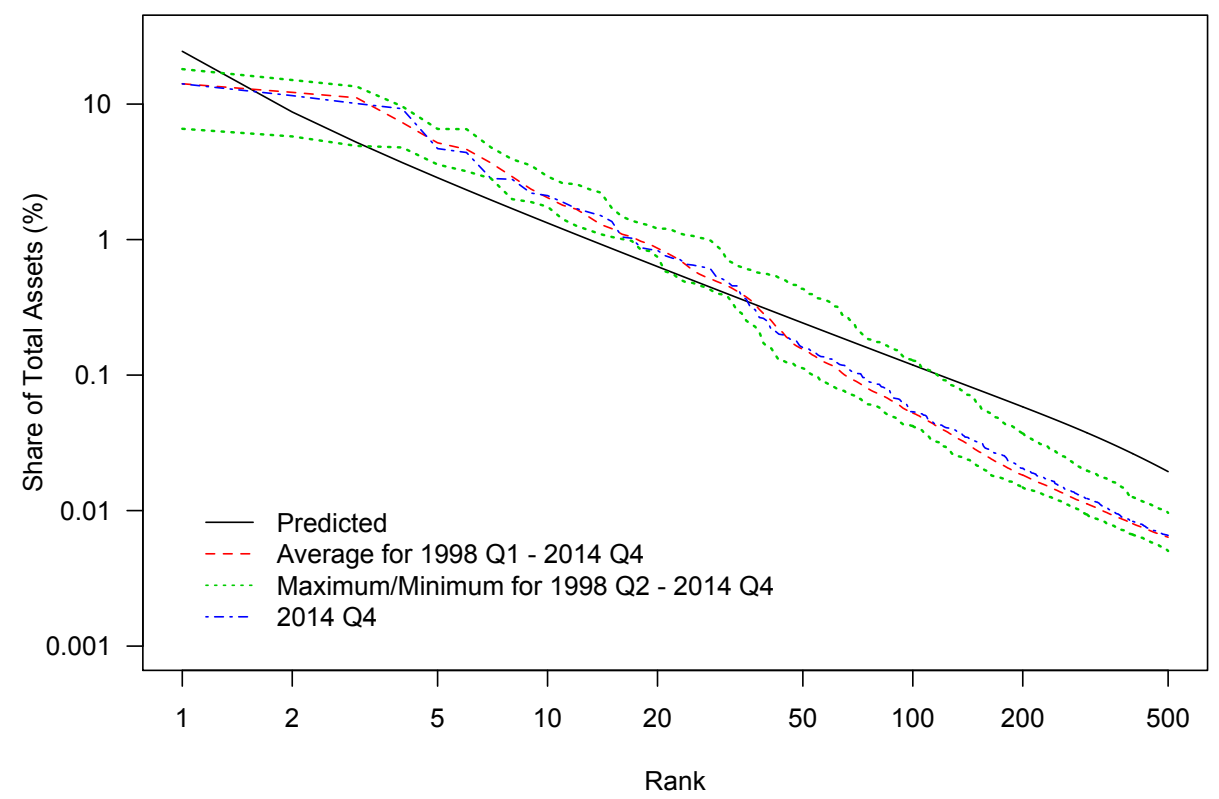

Fig. 11: Shares of total assets held by the 500 largest U.S. BHCs for 1998 Q1 - 2014 Q4 as compared to the predicted shares.

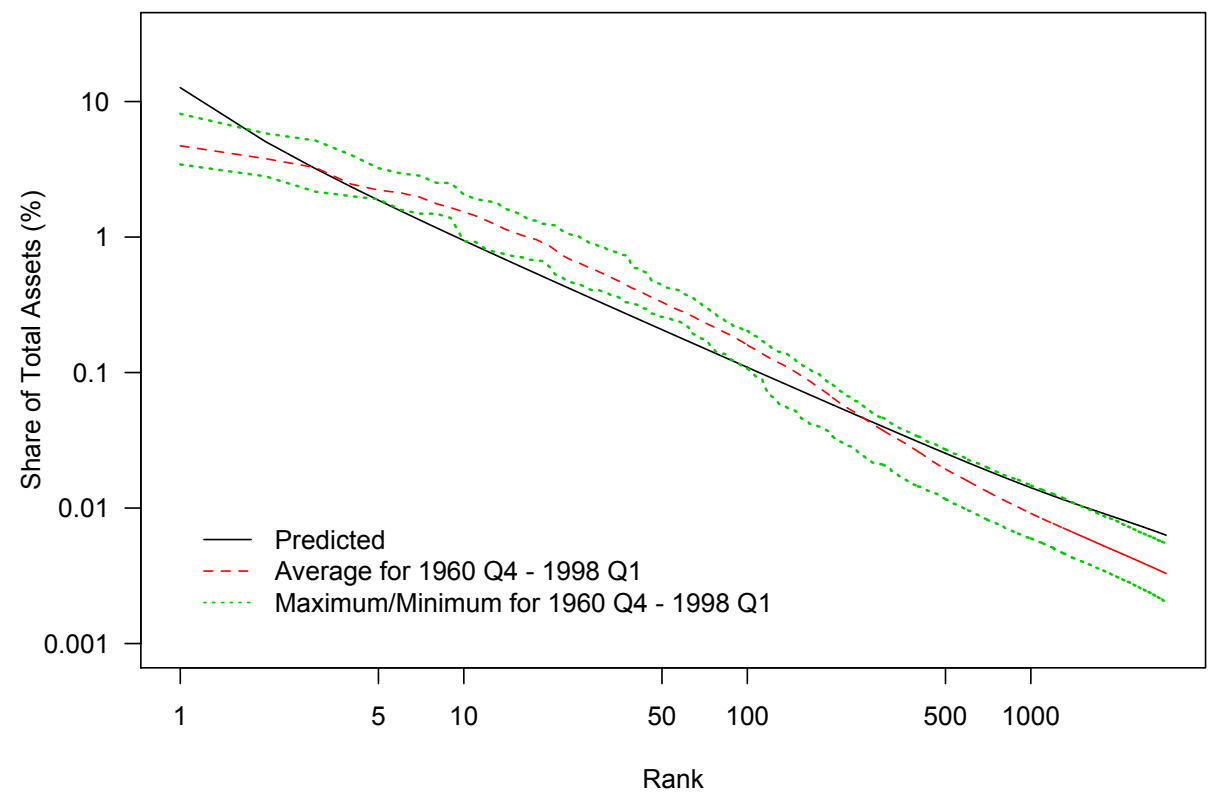

Fig. 12: Shares of total assets held by the 3,000 largest U.S. commercial banks for 1960 Q4 1998 Q1 as compared to the predicted shares. 


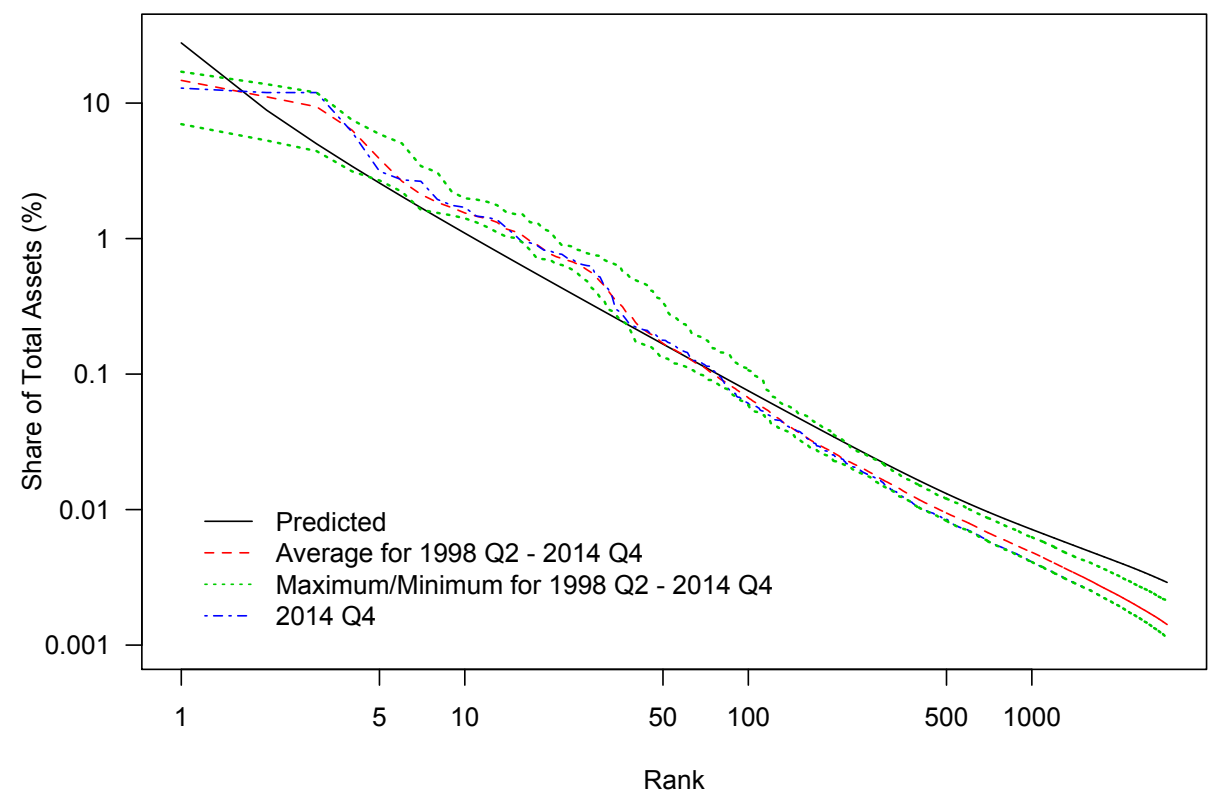

Fig. 13: Shares of total assets held by the 3,000 largest U.S. commercial banks for 1998 Q2 2014 Q4 as compared to the predicted shares.

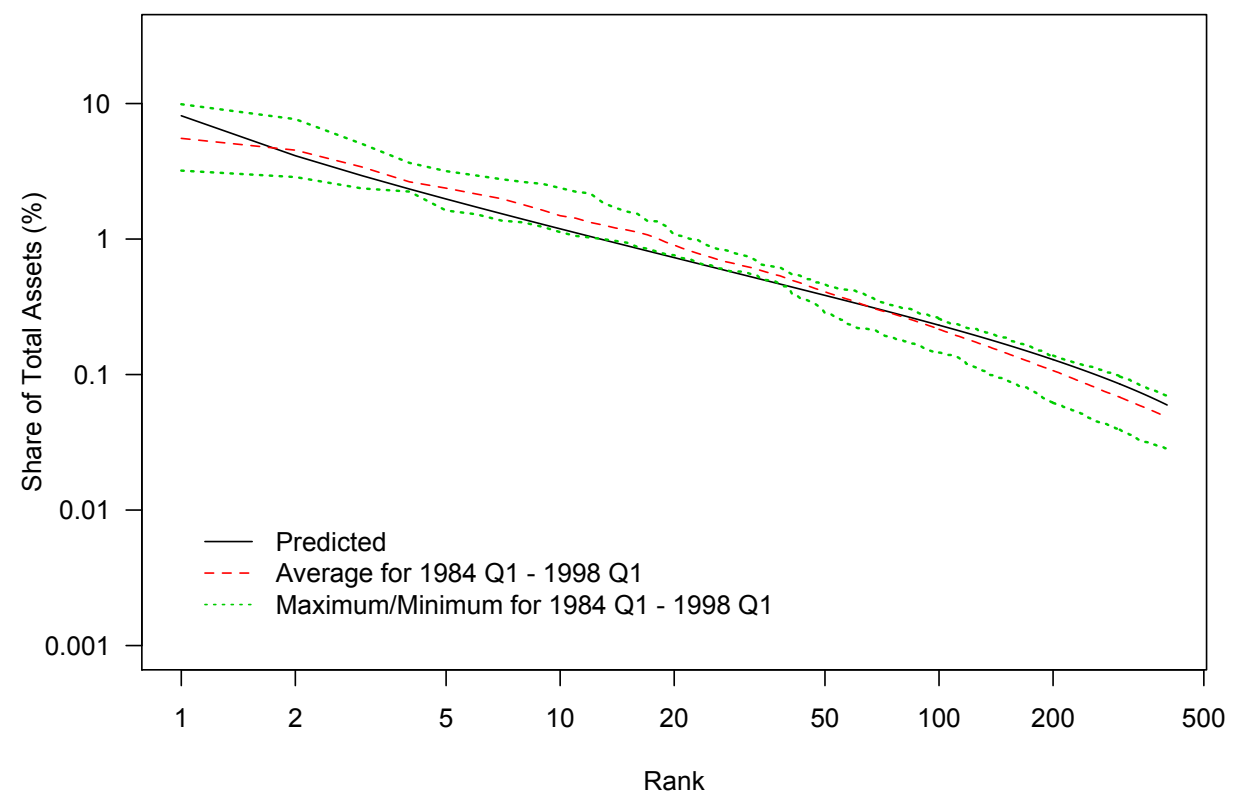

Fig. 14: Shares of total assets held by the 400 largest U.S. thrifts for 1984 Q1 - 1998 Q1 as compared to the predicted shares. 


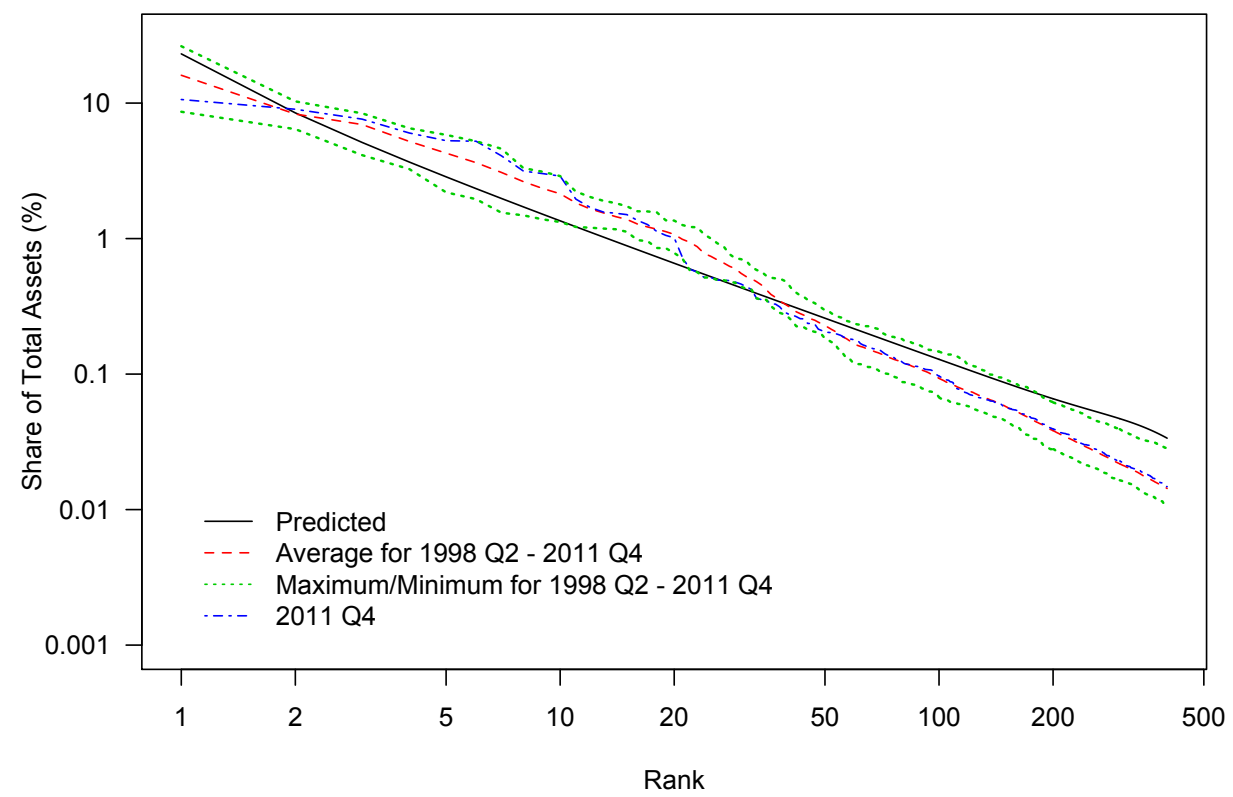

Fig. 15: Shares of total assets held by the 400 largest U.S. thrifts for 1998 Q2 - 2011 Q4 as compared to the predicted shares.

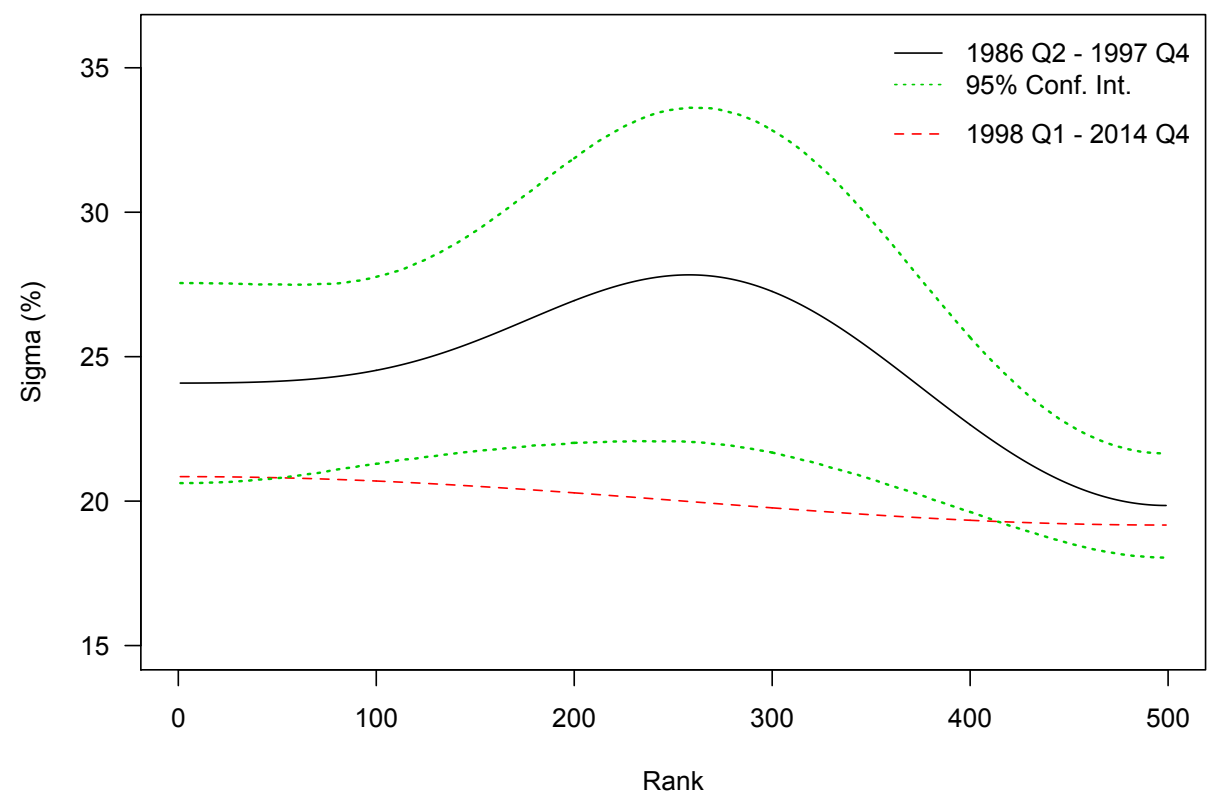

Fig. 16: Standard deviations of idiosyncratic asset volatilities $\left(\sigma_{k}\right)$ and $95 \%$ confidence intervals for different ranked U.S. bank-holding companies. 


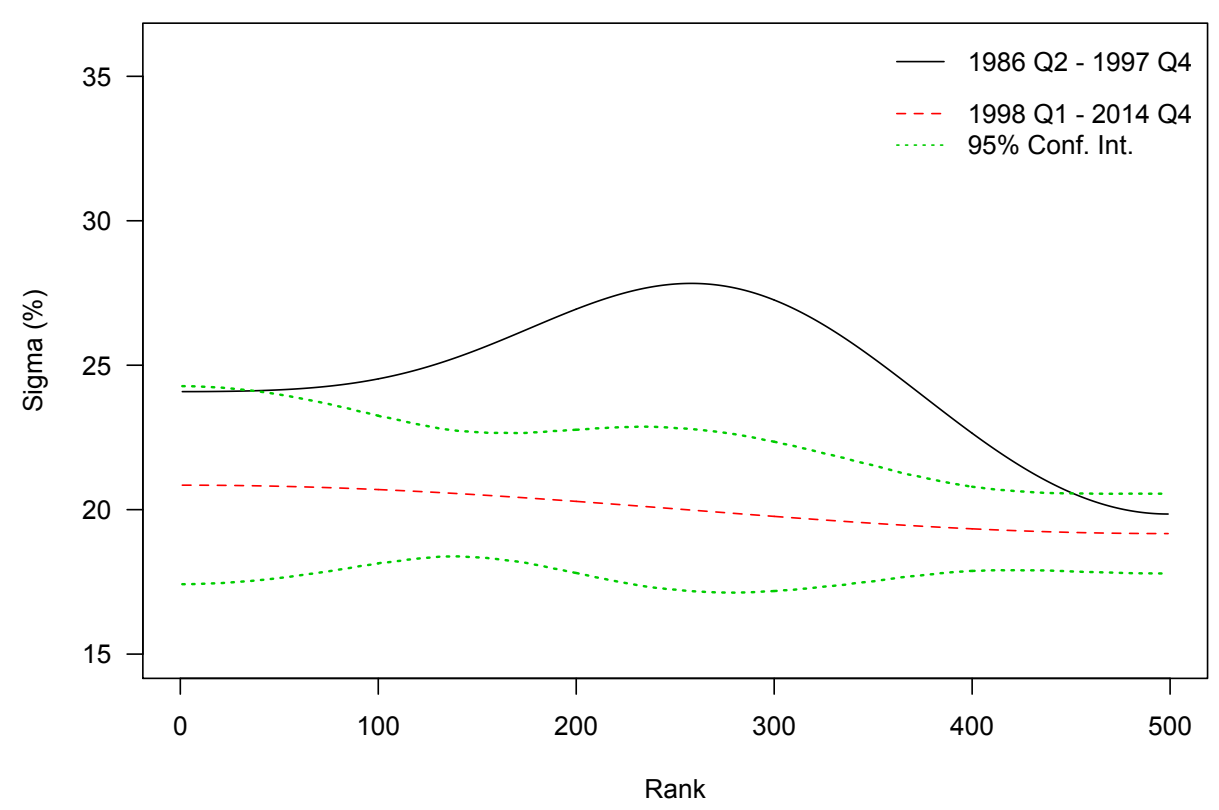

Fig. 17: Standard deviations of idiosyncratic asset volatilities $\left(\sigma_{k}\right)$ and $95 \%$ confidence intervals for different ranked U.S. bank-holding companies.

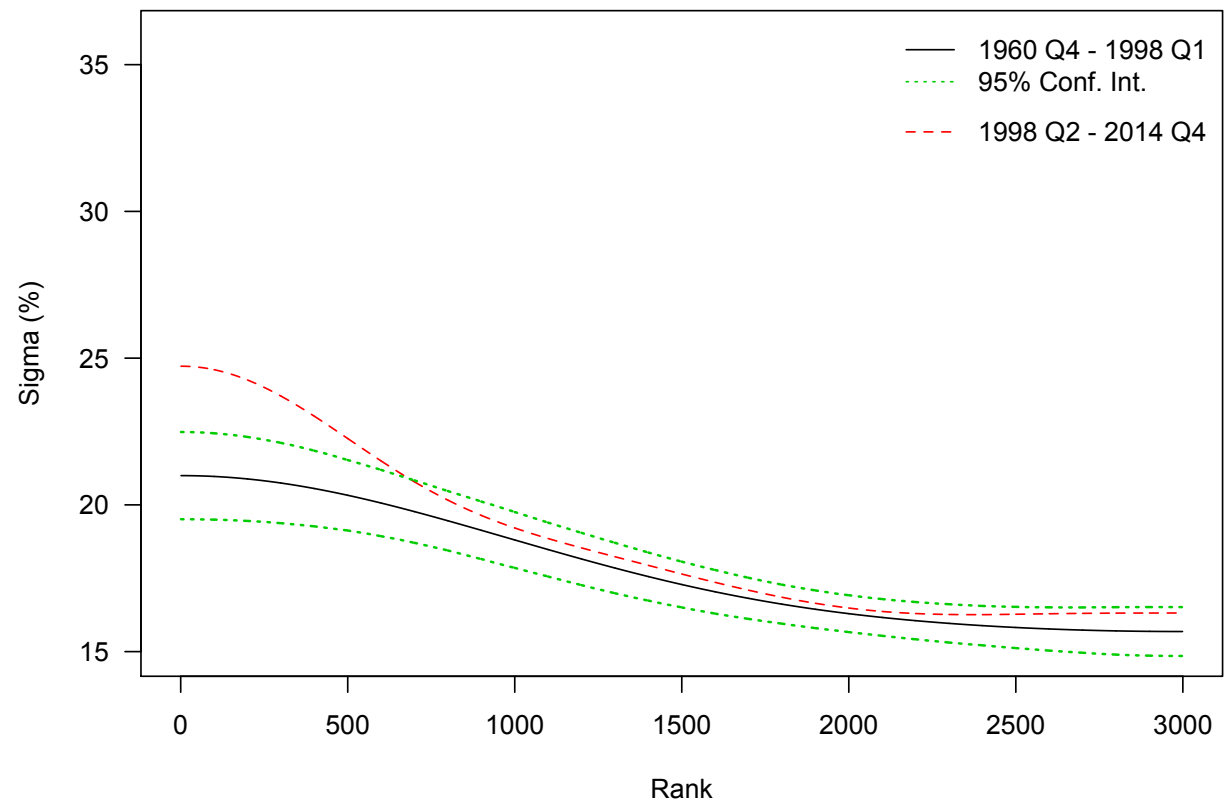

Fig. 18: Standard deviations of idiosyncratic asset volatilities $\left(\sigma_{k}\right)$ and $95 \%$ confidence intervals for different ranked U.S. commercial banks. 


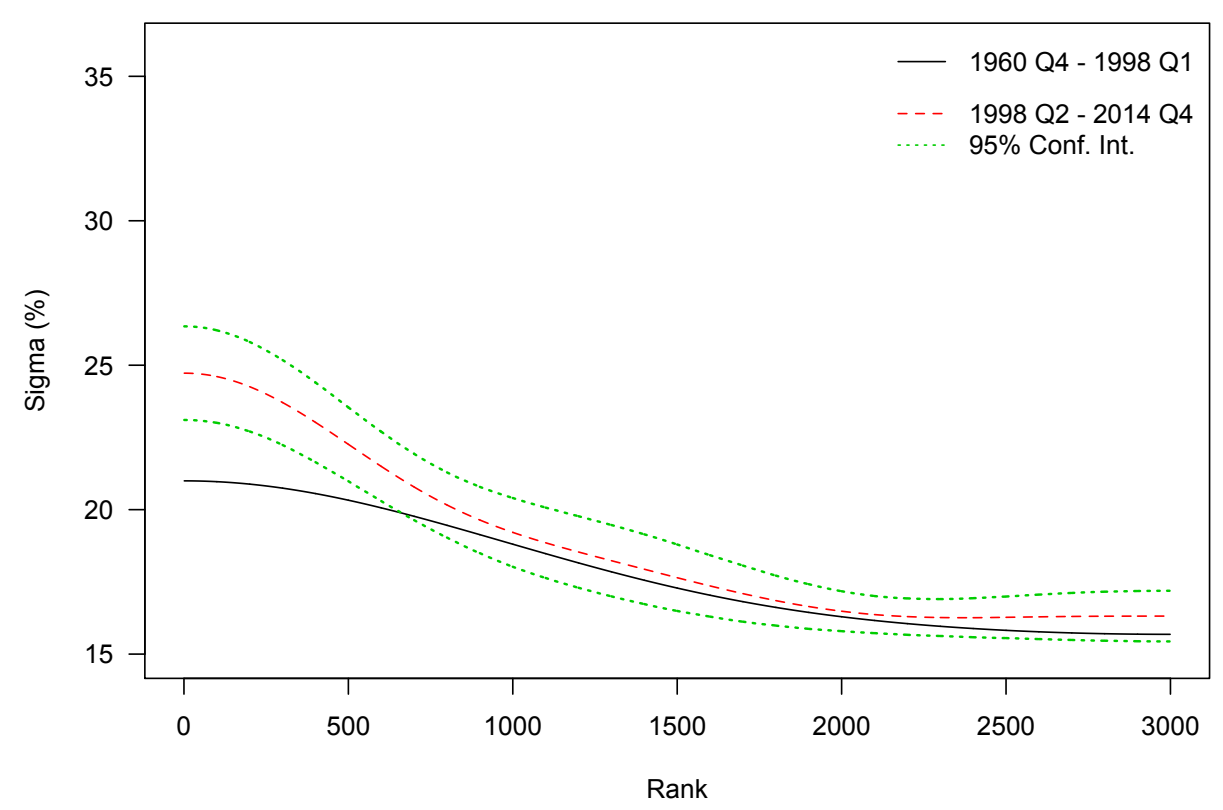

Fig. 19: Standard deviations of idiosyncratic asset volatilities $\left(\sigma_{k}\right)$ and $95 \%$ confidence intervals for different ranked U.S. commercial banks.

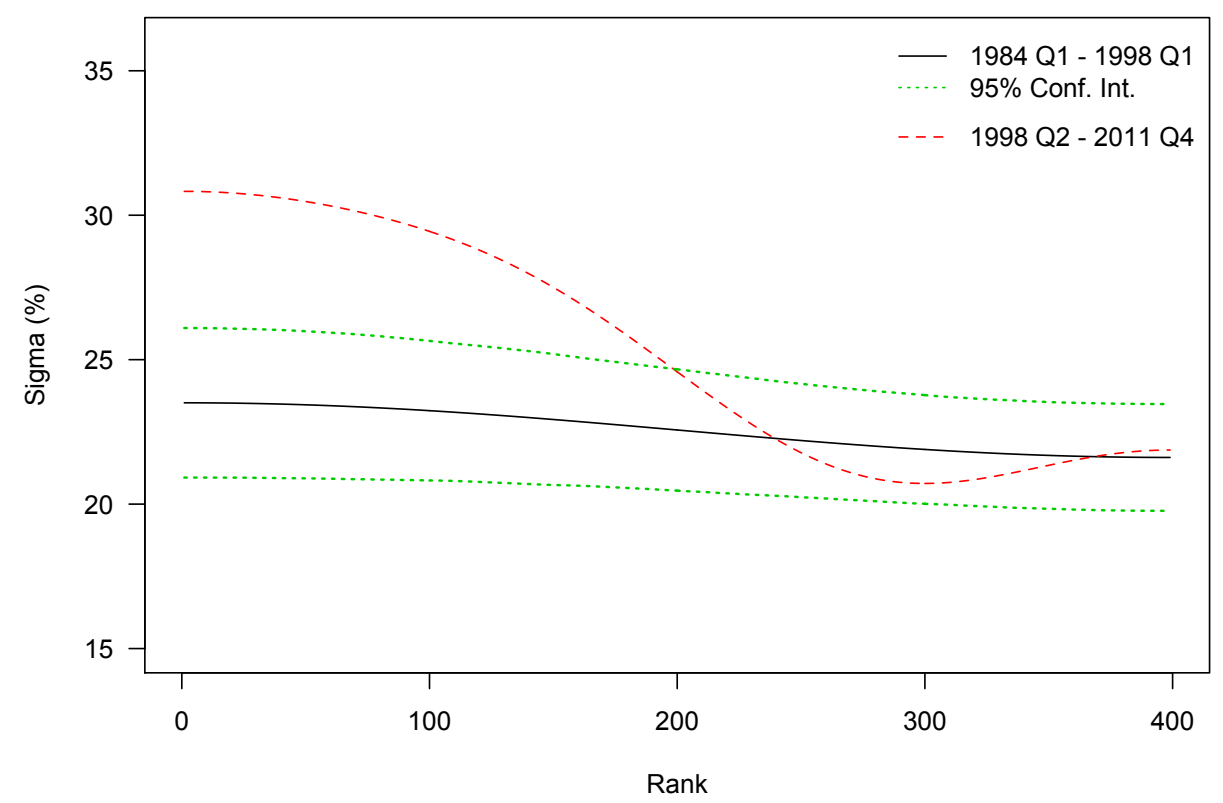

Fig. 20: Standard deviations of idiosyncratic asset volatilities $\left(\sigma_{k}\right)$ and $95 \%$ confidence intervals for different ranked U.S. thrifts. 


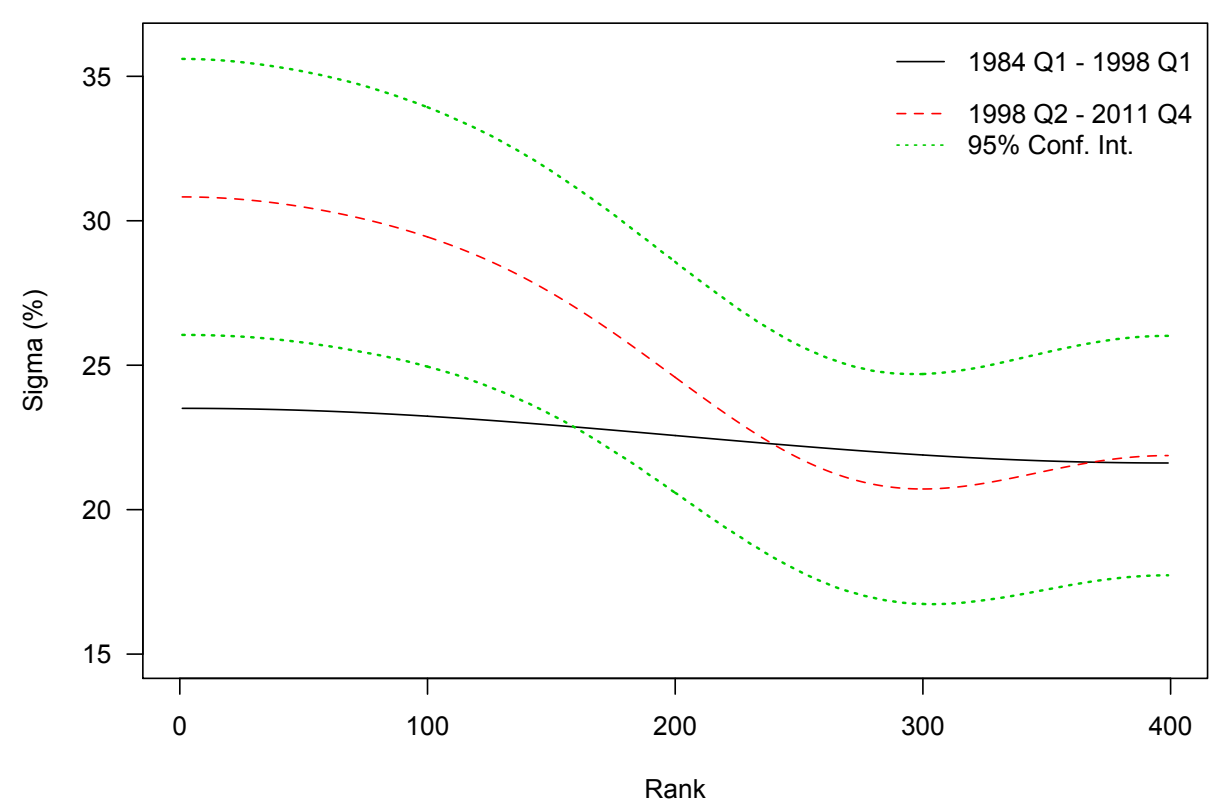

Fig. 21: Standard deviations of idiosyncratic asset volatilities $\left(\sigma_{k}\right)$ and $95 \%$ confidence intervals for different ranked U.S. thrifts.

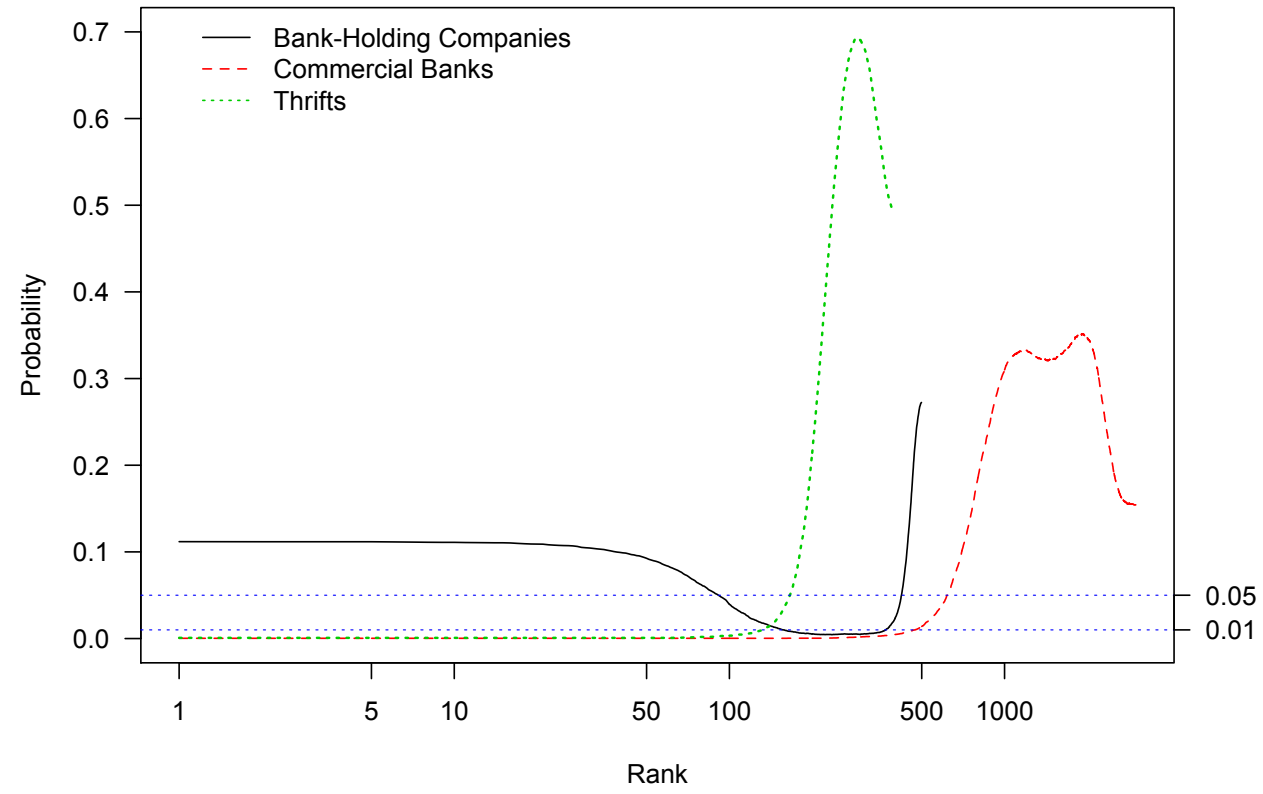

Fig. 22: Probability that $\sigma_{k}$ in time period 1 is greater (less) than or equal to $\sigma_{k}$ in time period 2 for different ranked U.S. commercial banks and thrifts (bank-holding companies). 